\title{
A practice guideline from the American College of Medical Genetics and Genomics and the National Society of Genetic Counselors: referral indications for cancer predisposition assessment
}

\author{
Heather Hampel, MS, LGC1, Robin L. Bennett, MS, LGC², Adam Buchanan, MS, MPH³, \\ Rachel Pearlman, MS, LGC1', and Georgia L. Wiesner, MD"; for a Guideline Development Group of the \\ American College of Medical Genetics and Genomics Professional Practice and Guidelines Committee \\ and of the National Society of Genetic Counselors Practice Guidelines Committee
}

\begin{abstract}
Disclaimer: The practice guidelines of the American College of Medical Genetics and Genomics (ACMG) and the National Society of Genetic Counselors (NSGC) are developed by members of the ACMG and NSGC to assist medical geneticists, genetic counselors, and other health-care providers in making decisions about appropriate management of genetic concerns, including access to and/or delivery of services. Each practice guideline focuses on a clinical or practice-based issue and is the result of a review and analysis of current professional literature believed to be reliable. As such, information and recommendations within the ACMG and NSGC joint practice guidelines reflect the current scientific and clinical knowledge at the time of publication, are current only as of their publication date, and are subject to change without notice as advances emerge. In addition, variations in practice, which take into account the needs of the individual patient and the resources and limitations unique to the institution or type of practice, may warrant approaches, treatments, and/ or procedures that differ from the recommendations outlined in this guideline. Therefore, these recommendations should not be construed as dictating an exclusive course of management, nor does the use of such recommendations guarantee a particular outcome. Genetic counseling practice guidelines are never intended to displace a health-care provider's best medical judgment based on the clinical circumstances of a particular patient or patient population. Practice guidelines are published by the ACMG or the NSGC for educational and informational purposes only, and neither the ACMG nor the NSGC "approve" or "endorse" any specific methods, practices, or sources of information.
\end{abstract}

Cancer genetic consultation is an important aspect of the care of individuals at increased risk of a hereditary cancer syndrome. Yet several patient, clinician, and system-level barriers hinder identification of individuals appropriate for cancer genetics referral. Thus, the purpose of this practice guideline is to present a single set of comprehensive personal and family history criteria to facilitate identification and maximize appropriate referral of at-risk individuals for cancer genetic consultation. To develop this guideline, a literature search for hereditary cancer susceptibility syndromes was conducted using PubMed. In addition, GeneReviews and the National Comprehensive Cancer Network guidelines were reviewed when applicable. When conflicting guidelines were identified, the evidence was ranked as follows: position papers from national and professional organizations ranked highest, followed by consortium guidelines, and then peerreviewed publications from single institutions. The criteria for cancer genetic consultation referral are provided in two formats: (i) tables that list the tumor type along with the criteria that, if met, would warrant a referral for a cancer genetic consultation and (ii) an alphabetical list of the syndromes, including a brief summary of each and the rationale for the referral criteria that were selected. Consider referral for a cancer genetic consultation if your patient or any of their firstdegree relatives meet any of these referral criteria.

Genet Med advance online publication 13 November 2014

Key Words: cancer genetics; cancer predisposition; genetic counseling; referral guidelines; referral indications
Cancer genetic consultation services include the evaluation of patients' personal and family history for concerning features of hereditary cancer predisposition syndromes, development of a differential diagnosis for one or more possible hereditary cancer syndromes, genetic testing if indicated and available, recommendations for management, cancer surveillance and prevention, and information regarding genetic counseling and genetic testing for at-risk relatives. This counseling is informed by the genetic

${ }^{1}$ Division of Human Genetics, Department of Internal Medicine, The Ohio State University Comprehensive Cancer Center, Columbus, Ohio, USA; ${ }^{2}$ Genetic Medicine Clinic, Department of Medicine, University of Washington Medical Center, Seattle, Washington, USA; ${ }^{3}$ Cancer Prevention, Detection and Control Research Program, Duke Cancer Institute, Duke University, Durham, North Carolina, USA; ${ }^{4}$ Clinical and Translational Hereditary Cancer Program, Division of Genetic Medicine, Department of Medicine, Vanderbilt-Ingram Cancer Center, Vanderbilt University, Nashville, Tennessee, USA. Correspondence: Heather Hampel (Heather.Hampel@osumc.edu)

(C)2014 American College of Medical Genetics and Genomics and National Society of Genetic Counselors. All rights reserved. This document may not, in whole or in part, be reproduced, copied or disseminated, entered into or stored in a computer database or retrieval system, or otherwise utilized without the prior written consent of both the American College of Medical Genetics and Genomics and the National Society of Genetic Counselors. 
risk assessment or diagnosis, which typically includes personal and family history, genetic and other laboratory results, results from procedures and imaging studies, and physical examination findings. Genetic counseling is an important component of the genetic consultation; it entails a discussion about the clinical and genetic aspects of a suspected diagnosis-including the mode of inheritance, identification of family members at risk, and discussion of the benefits, risks, and limitations of genetic testing and the alternative to not test-and helps patients make informed decisions about genetic testing considering their health-care needs, preferences, and values. Genetic testing performed without pre- and posttest genetic counseling by qualified clinicians has been associated with negative patient and societal outcomes such as misinterpretation of genetic test results, inappropriate medical management, lack of informed decision making, violation of established ethical standards, adverse psychosocial outcomes, and costly, unnecessary genetic testing. ${ }^{1-3}$

Cancer genetic consultation is an important aspect of the care of individuals at increased risk of a hereditary cancer syndrome. ${ }^{4-8}$ Yet, several patient, clinician, and system-level barriers hinder the identification of individuals appropriate for cancer genetics referral. In addition to limited time for the clinician to collect family history necessary to trigger a refer$\mathrm{ral}^{9-11}$ and limited patient awareness of their family cancer history, ${ }^{12}$ identifying appropriate patients is complicated by an abundance of complex criteria and guidelines that often differ from each other. ${ }^{13}$ Thus, the purpose of this practice guideline is to present a single set of comprehensive personal and family history criteria to facilitate identification and maximize appropriate referral of at-risk individuals for cancer genetic consultation. The criteria in this guidance statement are not designed to dictate what, if any, genetic testing is indicated or to recommend any specific cancer screening or treatment management.

Health-care providers have been encouraged to take a thorough family history from their patients and to refer them to genetic providers if the history is suspicious for a hereditary condition. Determining whom to refer is difficult for clinicians who do not specialize in cancer genetics, who may rarely encounter these syndromes, and who may not be familiar with the types of cancers known to be associated with a particular syndrome. These referral guidelines were developed in a table format so that the health-care provider can simply look up the cancer(s) that have been reported in a family and determine whether the personal or family history meets any of the criteria that warrant a referral. We include a short summary of each syndrome that explains the rationale behind the referral criteria in the Recommendations section of this guideline.

\section{MATERIALS AND METHODS}

To develop this guideline, a literature search for each of the hereditary cancer susceptibility syndromes described below was conducted using PubMed. In addition, GeneReviews (http:// www.genereviews.org) and the National Comprehensive Cancer Network guidelines (http://www.nccn.org/professionals/physician_gls/f_guidelines.asp) were reviewed when applicable. The searches were conducted between 1 December 2012 and 20 June 2013 and included the following search terms: hereditary cancer syndromes, referral criteria, guidelines, testing, mutation likelihood, and each syndrome's specific name. When conflicting guidelines were identified, the following processes were used to select the referral criteria for inclusion in this practice guideline. We ranked the sources of the differing guidelines. Position papers from national and professional organizations ranked highest, followed by consortium guidelines and then peerreviewed publications from single institutions. When guidelines from national and professional organizations differed, an attempt was made to select the least restrictive (i.e., most inclusive) set of referral criteria, as long as we felt it would not result in too many inappropriate referrals. For example, the National Comprehensive Cancer Network offers both evaluation criteria and genetic testing criteria for hereditary breast-ovarian cancer syndrome. We believe that the evaluation guidelines would result in an unmanageable number of referrals with little yield to patients and therefore chose the National Comprehensive Cancer Network genetic testing recommendations.

\section{RECOMMENDATIONS}

The criteria for cancer genetic consultation referral are detailed in Tables 1 and 2. Table 1 includes an alphabetical list of common cancers along with the criteria that, if met, would warrant a referral for a cancer genetic consultation. Table 2 includes the same information based on an alphabetical list of rare cancers. Referring to the tables in the clinic when a cancer is noted in a family history may be helpful to quickly determine whether a referral is indicated. If the family or individual meets the referral guideline for a particular syndrome, a brief summary of the syndrome and the rationale for the referral criteria can be found listed alphabetically in the text below. More detailed information about these syndromes can be found elsewhere. ${ }^{14}$

Consider referral for a cancer genetic consultation if your patients or any of their first-degree relatives meet any of these criteria. All affected relatives must be on the same side of the family. For the purposes of these guidelines, close relatives include first-degree relatives such as parents, siblings, and children, and second-degree relatives such as aunts, uncles, nieces, nephews, grandparents, and grandchildren. Please note that all the syndromes described in this guideline are inherited in an autosomal dominant manner, except where otherwise noted. Finally, any individual in a family with a known mutation in a cancer susceptibility gene should be referred for cancer genetic consultation.

\section{Birt-Hogg-Dubé syndrome (OMIM 135150)}

Birt-Hogg-Dubé syndrome is caused by mutations in the $F L C N$ gene and is characterized by the presence of classic skin lesions (fibrofolliculomas, perifollicular fibromas, trichodiscomas or angiofibromas, and acrochordons), bilateral and multifocal renal tumors (chromophobe clear cell renal carcinoma, renal oncocytoma, oncocytic hybrid tumor, and less often, clear cell renal carcinoma), and multiple bilateral lung cysts often associated with spontaneous pneumothorax. ${ }^{15}$ 
Table 1 Common benign and malignant tumors and the criteria that warrant assessment for cancer predisposition

\author{
Cancer/feature \\ (patient or FDR) \\ $B C C$
}

Brain

Brain
When to refer to genetic counseling

- $>5$ cumulative BCCs or BCC $d x$ at age $<30$ and one additional NBCCS criterion (Table 7) in the same person

- Brain tumor $\mathrm{dx}$ at age $<18$ if any of the following criteria are met: -Café-au-lait macules and/or other signs of NF1, or hypopigmented skin lesions -Consanguineous parents

-Family history of LS-associated cancer

-Second primary cancer

-Sibling with a childhood cancer

- Brain tumor and two additional cases of any LS-associated cancer (Table 6) in the same person or in relatives

- Brain tumor and one additional LFS tumor (Table 5) in the same person or in two relatives, one $\mathrm{dx}$ at age $\leq 45$

- Astrocytoma and melanoma in the same person or in two FDRs

- Subependymal giant cell astrocytoma and one additional TSC criterion (Table 8) in the same person

- Medulloblastoma and $\geq 10$ cumulative adenomatous colon polyps in the same person

- Medulloblastoma (PNET) dx at age $<18$ and one additional NBCCS criterion (Table 7) in the same person

Breast cancer, female $\quad$ Breast cancer $\mathrm{dx}$ at age $\leq 50$

- Triple-negative breast cancer $\mathrm{dx}$ at age $\leq 60$

- $\geq 2$ primary breast cancers in the same person

- Ashkenazi Jewish ancestry and breast cancer at any age

- $\geq 3$ cases of breast, ovarian, pancreatic, and/or aggressive prostate cancer in close relatives, including the patient

- Breast cancer and one additional LFS tumor (Table 5 ) in the same person or in two relatives, one $\mathrm{dx}$ at age $\leq 45$

- Breast cancer and $\geq 1$ PJ polyp in the same person

- Lobular breast cancer and diffuse gastric cancer in the same person

- Lobular breast cancer in one relative and diffuse gastric cancer in another, one $d x$ at age $<50$

- Breast cancer and two additional Cowden syndrome criteria (Table 4) in the same person

Breast cancer, male

Colorectal cancer
- Single case present

- Colorectal cancer dx at age $<50$

- Colorectal cancer $\mathrm{dx}$ at age $\geq 50$ if there is a FDR with colorectal or endometrial cancer at any age

- Synchronous or metachronous colorectal or endometrial cancers in the same person

- Colorectal cancer showing mismatch repair deficiency on tumor screening

- Colorectal cancer and two additional cases of any LS-associated cancer (Table 6) in the same person or in close relatives

- Colorectal cancer and two additional Cowden syndrome criteria (Table 4) in the same person

- Colorectal cancer and one additional LFS tumor (Table 5) in the same person or in two relatives, one $\mathrm{dx}$ at age $\leq 45$

- Colorectal cancer with $\geq 10$ cumulative adenomatous colon polyps in the same person
Syndrome(s) to consider

NBCCS, OMIM 109400

CMMRD,OMIM 276300

LS, OMIM 120435, 120436

LFS, OMIM 151623

MAS, OMIM 155755

TSC, OMIM 191100

FAP, OMIM 175100

NBCCS, OMIM 109400

HBOC, OMIM: 604370, 612555; LFS, OMIM 151623

PJS, OMIM 175200

HDGC, OMIM 137215

Cowden, OMIM 158350

HBOC, OMIM: 604370, 612555

LS, OMIM 120435, 120436; CMMRD

OMIM 276300; MAP, OMIM 608456

Cowden, OMIM 158350

LFS, OMIM 151623

FAP, OMIM 175100; MAP, OMIM 608456

Refer for a cancer predisposition assessment if your patients or any of their first-degree relatives (FDRs) meet any of the criteria. All affected relatives must be on the same side of the family. For the purposes of these guidelines, close relatives include the patient's parents, siblings, children, aunts, uncles, nieces, nephews, grandparents, and grandchildren.

BCC, basal cell carcinoma; BHD, Birt-Hogg-Dubé syndrome; CMMRD, constitutional mismatch repair deficiency; dx, diagnosed; FAP, familial adenomatous polyposis; FP, familial prostate cancer; FPC, familial pancreatic cancer; Gl, gastrointestinal; HBOC, hereditary breast-ovarian cancer syndrome; HDGC, hereditary diffuse gastric cancer; HLRCC, hereditary leiomyomatosis and renal cell carcinoma; HM, familial atypical mole and malignant melanoma; HMPS, hereditary mixed polyposis syndrome; HPRC, hereditary papillary renal cancer; JPS, juvenile polyposis syndrome; LFS, Li-Fraumeni syndrome; LS, Lynch syndrome; MAP, MUTYH-associated polyposis; MAS, melanoma astrocytoma syndrome; MEN2, multiple endocrine neoplasia type 2; NBCCS, nevoid basal cell carcinoma syndrome; NF1, neurofibromatosis type 1; PJ, Peutz-Jeghers; PJS, Peutz-Jeghers syndrome; RCC, renal cell carcinoma; SP, serrated polyp, which includes hyperplastic polyps, sessile serrated polyps/adenomas, and traditional serrated polyps; SPS, serrated polyposis syndrome; TSC, tuberous sclerosis complex; VHL, Von Hippel-Lindau syndrome. 
Table 1 Continued

\section{Cancer/feature (patient or FDR)}

Colorectal polyposis, adenomatous

Colorectal polyposis, hamartomatous

Colorectal polyposis,
serrated

When to refer to genetic counseling

- $\geq 10$ cumulative adenomatous colon polyps in the same person

- 3-5 cumulative histologically proven juvenile polyps in the same person

- Multiple juvenile polyps throughout the GI tract in the same person

- Any number of juvenile polyps with a positive family history of JPS

- $\geq 2$ cumulative histologically proven PJ polyps in the same person

- $\geq 1$ PJ polyp and mucocutaneous hyperpigmentation in the same person

- Any number of PJ polyps and a positive family history of PJS

- Gl hamartoma or ganglioneuroma and two additional Cowden syndrome criteria (Table 4) in the same person

- Rectal hamartomatous polyps and one additional TSC criterion (Table 8) in the same person

- Diffuse ganglioneuromatosis of the GI tract

- $\geq 5 \mathrm{SPs}$ proximal to the sigmoid colon, two of which are $>1 \mathrm{~cm}$ in diameter, in the same person

- $>20$ SPs at any site in the large bowel in the same person

- Any number of SPs proximal to the sigmoid colon and a positive family history of SPS

Colorectal polyposis, $\quad \bullet \geq 10$ cumulative polyps with $>1$ histology in the same person

mixed

Endometrial cancer

- Endometrial cancer $\mathrm{dx}$ at age $<50$
- Endometrial cancer $\mathrm{dx}$ at age $\geq 50$ if there is a FDR with colorectal or endometrial cancer at any age

- Synchronous or metachronous colorectal or endometrial cancer in the same person

Endometrial cancer showing mismatch repair deficiency on tumor screening

- Endometrial cancer and 2 additional cases of any LS-associated cancer (Table 6) in the same person or in close relatives

- Epithelial endometrial cancer and two additional Cowden syndrome criteria (Table 4) in the same person

\begin{tabular}{|c|c|}
\hline Gastric cancer & $\begin{array}{l}\text { - } \geq 2 \text { cases of gastric cancer, one } \mathrm{dx} \text { at age }<50 \text { in close relatives } \\
\text { - } \geq 3 \text { cases of gastric cancer in close relatives } \\
\text { - Diffuse gastric cancer } \mathrm{dx} \text { at age }<40 \\
\text { - Diffuse gastric cancer and lobular breast cancer in the same person } \\
\text { - Diffuse gastric cancer in one relative and lobular breast cancer in another, one } \\
\text { at age }<50 \\
\text { - Gastric cancer and } 2 \text { additional cases of any LS-associated cancer (Table 6) in th } \\
\text { same person or in close relatives }\end{array}$ \\
\hline Leukemia & $\begin{array}{l}\text { - Leukemia } \mathrm{dx} \text { at age }<18 \text {, if any of the following criteria are met: } \\
\text {-Café-au-lait macules and/or other signs of NF1, or hypopigmented skin lesions } \\
\text {-Consanguineous parents } \\
\text {-Family history of LS-associated cancers } \\
\text {-Second primary cancer } \\
\text {-Sibling with a childhood cancer }\end{array}$ \\
\hline
\end{tabular}

- Leukemia and one additional LFS tumor (Table 5) in the same person or in 2 close relatives, one $d x$ at age $\leq 45$
Syndrome(s) to consider

FAP, OMIM 175100; MAP, OMIM 608456

JPS, OMIM 174900

PJS, OMIM 175200

Cowden, OMIM 158350

TSC, OMIM 191100

MEN2, OMIM 171400

SPS, not in OMIM

HMPS, OMIM 201228, 610069

LS, OMIM 120435, 120436

Cowden, OMIM 158350

HDGC, OMIM 137215

LS, OMIM 120435, 120436

CMMRD, OMIM 276300

Refer for a cancer predisposition assessment if your patients or any of their first-degree relatives (FDRs) meet any of the criteria. All affected relatives must be on the same side of the family. For the purposes of these guidelines, close relatives include the patient's parents, siblings, children, aunts, uncles, nieces, nephews, grandparents, and grandchildren.

BCC, basal cell carcinoma; BHD, Birt-Hogg-Dubé syndrome; CMMRD, constitutional mismatch repair deficiency; dx, diagnosed; FAP, familial adenomatous polyposis; FP, familial prostate cancer; FPC, familial pancreatic cancer; GI, gastrointestinal; $\mathrm{HBOC}$, hereditary breast-ovarian cancer syndrome; HDGC, hereditary diffuse gastric cancer; HLRCC, hereditary leiomyomatosis and renal cell carcinoma; HM, familial atypical mole and malignant melanoma; HMPS, hereditary mixed polyposis syndrome; HPRC, hereditary papillary renal cancer; JPS, juvenile polyposis syndrome; LFS, Li-Fraumeni syndrome; LS, Lynch syndrome; MAP, MUTYH-associated polyposis; MAS, melanoma astrocytoma syndrome; MEN2, multiple endocrine neoplasia type 2; NBCCS, nevoid basal cell carcinoma syndrome; NF1, neurofibromatosis type 1; PJ, Peutz-Jeghers; PJS, Peutz-Jeghers syndrome; RCC, renal cell carcinoma; SP, serrated polyp, which includes hyperplastic polyps, sessile serrated polyps/adenomas, and traditional serrated polyps; SPS, serrated polyposis syndrome; TSC, tuberous sclerosis complex; VHL, Von Hippel-Lindau syndrome. 


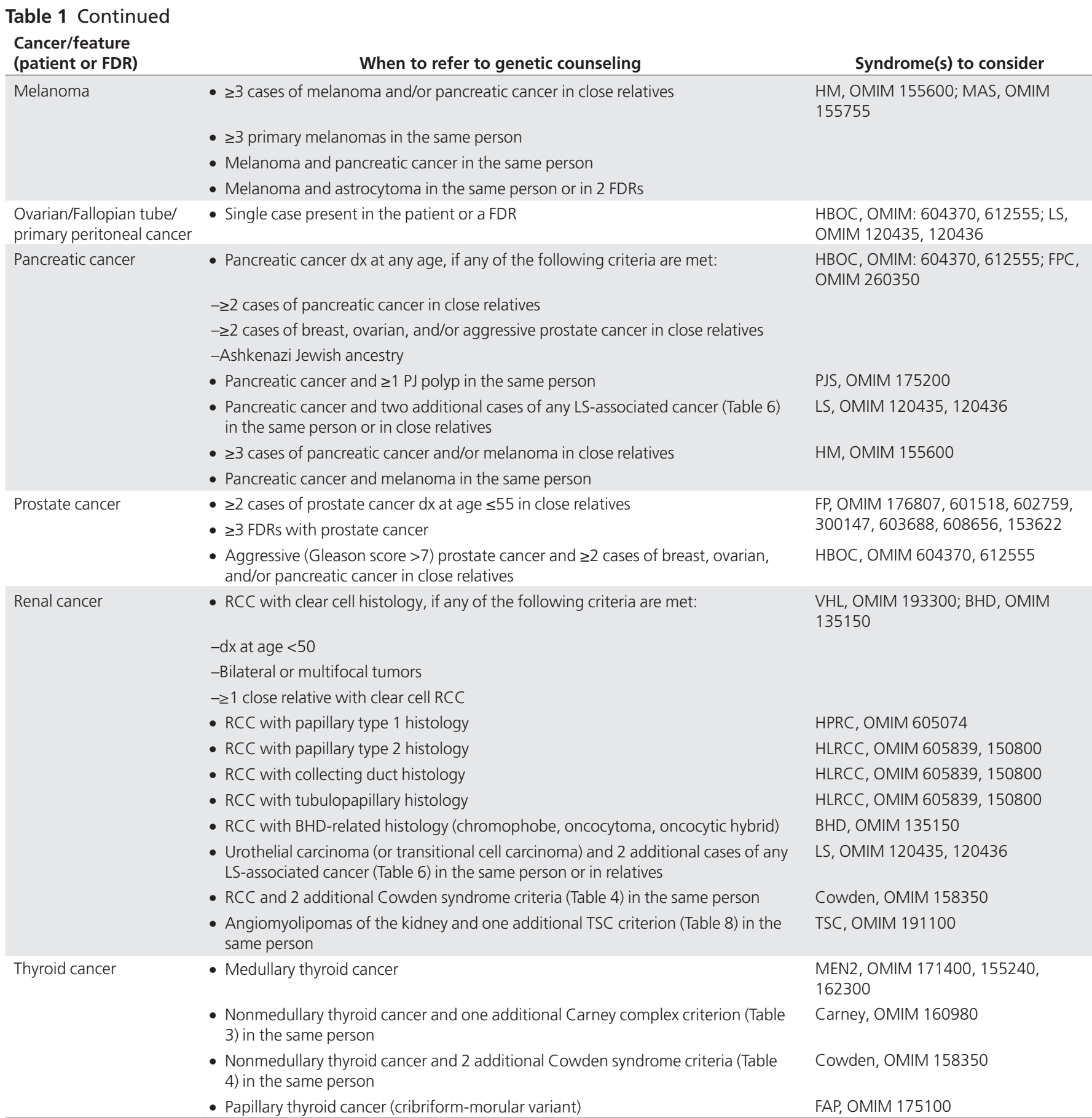

Refer for a cancer predisposition assessment if your patients or any of their first-degree relatives (FDRs) meet any of the criteria. All affected relatives must be on the same side of the family. For the purposes of these guidelines, close relatives include the patient's parents, siblings, children, aunts, uncles, nieces, nephews, grandparents, and grandchildren.

BCC, basal cell carcinoma; BHD, Birt-Hogg-Dubé syndrome; CMMRD, constitutional mismatch repair deficiency; dx, diagnosed; FAP, familial adenomatous polyposis; FP, familial prostate cancer; FPC, familial pancreatic cancer; GI, gastrointestinal; HBOC, hereditary breast-ovarian cancer syndrome; HDGC, hereditary diffuse gastric cancer; HLRCC, hereditary leiomyomatosis and renal cell carcinoma; HM, familial atypical mole and malignant melanoma; HMPS, hereditary mixed polyposis syndrome; HPRC, hereditary papillary renal cancer; JPS, juvenile polyposis syndrome; LFS, Li-Fraumeni syndrome; LS, Lynch syndrome; MAP, MUTYH-associated polyposis; MAS, melanoma astrocytoma syndrome; MEN2, multiple endocrine neoplasia type 2; NBCCS, nevoid basal cell carcinoma syndrome; NF1, neurofibromatosis type 1; PJ, Peutz-Jeghers; PJS, Peutz-Jeghers syndrome; RCC, renal cell carcinoma; SP, serrated polyp, which includes hyperplastic polyps, sessile serrated polyps/adenomas, and traditional serrated polyps; SPS, serrated polyposis syndrome; TSC, tuberous sclerosis complex; VHL, Von Hippel-Lindau syndrome.

Skin lesions typically occur in the 30 s and 40 s and increase with age. The median age at diagnosis of renal cell tumors is 48 years, with a range of $31-71$ years.
Referral should be considered for any individual with a personal history of or first-degree relative with (i) $\geq 5$ Birt-HoggDubé-associated facial or truncal papules; (ii) early-onset $(<50$ 
Table 2 Rare benign and malignant tumors and the criteria that warrant assessment for cancer predisposition

\section{Cancer/feature (patient or} FDR)
Adrenocortical tumor

Adrenal tumor

Brain

Breast
Bone cysts
Carcinoid tumor of foregut (e.g.,
thymic, bronchial)
Cardiac fibromas
Cardiac myxoma

Cardiac myxoma

Cardiac rhabdomyoma

Cervix, adenoma malignum

Dental pitting

Desmoid tumor

Endolymphatic sac tumor

Gastrinoma

GIST
When to refer to genetic counseling

- Single case present in the patient or a FDR

- Adrenal tumor and pancreatic neuroendocrine tumor, parathyroid adenoma, thymic or bronchial carcinoid tumor, or pituitary tumor in the same person

- Cortical tuber, subependymal nodule, or cerebral white matter "migration lines" and one additional TSC criterion (Table 8) in the same person

- Choroid plexus carcinoma (single case present) in the patient or a FDR

- Lhermitte-Duclos (dysplastic gangliocytoma of the cerebellum) dx at age $>18$

- Myxomatosis and one additional Carney complex criterion (Table 3) in the same person

- Multiple ductal adenomas and one additional Carney complex criterion (Table 3)

- Bone cysts and one additional TSC criterion (Table 8) in the same person

- Foregut carcinoid tumor and parathyroid adenoma, pancreatic neuroendocrine tumor, anterior pituitary tumor, or adrenal tumor in the same person

- Cardiac fibroma and one additional NBCCS criterion (Table 7) in the same person

- Cardiac myxoma and one additional Carney complex criterion (Table 3) in the same person

- Cardiac rhabdomyoma (especially prenatal/newborn) and one additional TSC criterion (Table 8) in the same person

- Single case present in the patient or a FDR

- Pitting in dental enamel and one additional TSC criterion (Table 8) in the same person

- Single case present in the patient or a FDR

- Single case present in the patient or a FDR

- Single case present in the patient or a FDR

- $\geq 3$ close relatives with GIST

- Wild-type GIST

- $\geq 3$ primary GISTs in the same person

Hemangioblastoma (CNS or retinal)

Hepatoblastoma
Lung cysts
Lymphangiomyomatosis

Osteochondromyxoma

Ovarian fibromas

- Single case present in the patient or a FDR

- $d x$ at age $<5$

- Lung cysts leading to multiple pneumothoraces

- Lymphangiomyomatosis and one additional TSC criterion (Table 8) in the same person

- Osteochondromyxoma and one additional Carney complex criterion (Table 3) in the same person

Ovarian sex cord tumor with annular tubules

Ovarian small cell carcinoma, hypercalcemic type

Pancreatic neuroendocrine tumor (e.g., gastrinoma, insulinoma, glucagonoma, VIPoma)

- Ovarian fibroma and one additional NBCCS criterion (Table 7) in the same person

- Single case present in the patient or a FDR

- Single case present in the patient or a FDR

- Pancreatic neuroendocrine tumor and parathyroid adenoma, thymic or bronchial carcinoid tumor, pituitary tumor, or adrenal tumor in the same person

- Multiple primary neuroendocrine tumors in the same person

- Gastrinoma in the patient or a FDR

Parathyroid adenoma

- Parathyroid adenoma dx at age $<30$ in the same person

Syndrome(s) to consider

LFS, OMIM 151623

MEN1, OMIM 131100

TSC, OMIM 191100

LFS, OMIM 151623

Cowden, OMIM 158350

Carney, OMIM 160980

Carney, OMIM 160980

TSC, OMIM 191100

MEN1, OMIM 131100

NBCCS, OMIM 109400

Carney, OMIM 160980

TSC, OMIM 191100

PJS, OMIM 175200

TSC, OMIM 191100

FAP, OMIM 175100

VHL, OMIM 193300

MEN1, OMIM 131100

Familial GIST, OMIM 606764

VHL, OMIM 193300

FAP,

BHD, OMIM; 135150

TSC, OMIM 191100

Carney, OMIM 160980

NBCCS, OMIM 109400

PJS, OMIM 175200

RPS, OMIM 613325

MEN1, OMIM 131100

- Parathyroid adenoma with multiple glands involved

- Parathyroid adenoma and thymic or bronchial carcinoid, pancreatic neuroendocrine tumor, pituitary tumor, or adrenal tumor in the same person

- Parathyroid adenoma and a family history of hyperparathyroidism, pituitary adenoma, pancreatic islet cell tumor, or foregut carcinoid tumor
MEN1, OMIM 131100; MEN2, OMIM 171400, 155240,162300

BHD, Birt-Hogg-Dubé syndrome; CNS, central nervous system; dx, diagnosed; FAP, familial adenomatous polyposis; FDR, first-degree relative; GIST, gastrointestinal stromal tumor; HLRCC, hereditary leiomyomatosis and renal cell carcinoma; HPPS, hereditary paraganglioma-pheochromocytoma syndrome; LFS, Li-Fraumeni syndrome; LS, Lynch syndrome; MEN1, multiple endocrine neoplasia type 1; MEN2, multiple endocrine neoplasia type 2; NBCCS, nevoid basal cell carcinoma syndrome; PJS, Peutz-Jeghers syndrome; PMS, psammomatous melanotic schwannoma; RB, retinoblastoma; RP, rhabdoid predisposition; RPS, rhabdoid predisposition syndrome; TSC, tuberous sclerosis complex; VHL, Von Hippel-Lindau syndrome; VIP, vasoactive intestinal peptide.

Table 2 Continued on next page 
Table 2 Continued

Cancer/feature (patient or FDR)

Pheochromocytoma/

paraganglioma

When to refer to genetic counseling

- Single case present in the patient or a FDR

Pituitary adenoma

- Pituitary adenoma and parathyroid adenoma, pancreatic neuroendocrine tumor, thymic or bronchial carcinoid, or adrenal tumor in the same person

- Growth hormone-producing adenoma with acromegaly and one additional Carney complex criterion (Table 3) in the same person

Primary pigmented nodular

- Single case present in the patient or a FDR

adrenocortical dysplasia

Psammomatous melanotic

- PMS and one additional Carney complex criterion (Table 3) in the same person schwannoma

Renal cysts

Retinal achromic patch

Retinal hamartoma

Retinoblastoma

Rhabdoid tumors

Sarcoma (non-Ewing sarcoma)

Skin (rare)

- Renal cysts and one additional TSC criterion (Table 8) in the same person

- Retinal hamartoma and one additional TSC criterion (Table 8) in the same person

- Single case present in the patient or a FDR

- Single case present in the patient or a FDR

- Sarcoma and one additional LFS tumor (Table 5) in the same person or in 2 close relatives, one $d x$ at age $\leq 45$

- Sarcoma dx at age $<18$

- Single case present in the patient or a FDR

- Large cell calcifying histology and one additional Carney complex criterion (Table 3) in the same person or a FDR

- Spotty skin pigmentation on lips, conjunctiva and inner or outer canthi, and/or
- Retinal achromic patch and one additional TSC criterion (Table 8) in the same person vaginal or penile mucosa, and one additional Carney complex criterion (Table 3) in the same person

- Cutaneous or mucosal myxoma and one additional Carney complex criterion (Table 3) in the same person

- Epithelioid blue nevus and one additional Carney complex criterion (Table 3) in the same person

- Trichilemmoma ( $\geq 3$ ) and 2 additional Cowden syndrome criteria (Table 4) in the same person

- Acral keratoses ( $\geq 3$ ) and 2 additional Cowden syndrome criteria (Table 4) in the same person

- Oral papillomas and 2 additional Cowden syndrome criteria (Table 4) in the same person

- Oral or ocular neuromas (lip, tongue, eyelid, or sclera)

- Mucocutaneous neuromas and 2 additional Cowden syndrome criteria (Table 4) in the same person

- Macular pigmentation of glans penis and 2 additional Cowden syndrome criteria (Table 4) in the same person

- Cutaneous leiomyoma

- Sebaceous adenoma/carcinoma and one additional case of any LS-associated cancer (Table 6) in the same person or in relatives

- Palmar or plantar pitting and one additional NBCCS criterion (Table 7) in the same person

- Mucocutaneous pigmentation and $\geq 1$ PJ polyp in the same person

- Fibrofolliculomas, perifollicular fibromas, trichodiscomas/angiofibromas, and acrochordons ( $\geq 5)$

- Hypomelanotic macules, shagreen patch, ungual fibromas, facial angiofibromas, gingival fibroma, or "confetti" skins lesions and one additional TSC criterion (Table 8) in the same person
Syndrome(s) to consider

HPPS, OMIM 115310,

$168000,605373,601650$,

154950, 613403; VHL, OMIM

193300; MEN2, OMIM

$171400,155240,162300$

MEN1, OMIM 131100

Carney, OMIM 160980

Carney, OMIM 160980

Carney, OMIM 160980

TSC, OMIM 191100

TSC, OMIM 191100

TSC, OMIM 191100

Hereditary RB, OMIM 180200

RP, OMIM 609322, 613325

LFS, OMIM 151623

PJS, OMIM 175200

Carney, OMIM 160980

Carney, OMIM 160980

Carney, OMIM 160980

Carney, OMIM 160980

Cowden, OMIM 158350

Cowden, OMIM 158350

Cowden, OMIM 158350

MEN2, OMIM 171400,

155240,162300

Cowden, OMIM 158350

Cowden, OMIM 158350

HLRCC, OMIM 605839, 150800

LS, OMIM 120435, 120436

NBCCS, OMIM 109400

PJS, OMIM 175200

BHD, OMIM; 135150

TSC, OMIM 191100

BHD, Birt-Hogg-Dubé syndrome; CNS, central nervous system; dx, diagnosed; FAP, familial adenomatous polyposis; FDR, first-degree relative; GIST, gastrointestinal stromal tumor; HLRCC, hereditary leiomyomatosis and renal cell carcinoma; HPPS, hereditary paraganglioma-pheochromocytoma syndrome; LFS, Li-Fraumeni syndrome; LS, Lynch syndrome; MEN1, multiple endocrine neoplasia type 1; MEN2, multiple endocrine neoplasia type 2; NBCCS, nevoid basal cell carcinoma syndrome; PJS, Peutz-Jeghers syndrome; PMS, psammomatous melanotic schwannoma; RB, retinoblastoma; RP, rhabdoid predisposition; RPS, rhabdoid predisposition syndrome; TSC, tuberous sclerosis complex; VHL, Von Hippel-Lindau syndrome; VIP, vasoactive intestinal peptide. 
years old), bilateral or multifocal clear cell renal carcinoma; (iii) renal cancers with Birt-Hogg-Dubé histology (chromophobe, oncocytoma, or oncocytic hybrid); or (iv) lung cysts associated with multiple spontaneous pneumothoraxes. ${ }^{16,17}$

\section{Carney complex (OMIM 160980)}

Carney complex is caused by mutations in the PRKAR1A gene and is characterized by pale brown to black lentigenes; myxomas of the heart, skin, and breast; primary pigmented nodular adrenocortical disease; and large cell calcifying Sertoli cell tumors. Psammomatous melanotic schwannoma, a rare nerve sheath tumor, can also occur. At least $50 \%$ of individuals with isolated primary pigmented nodular adrenocortical disease have a PRKAR1A mutation. ${ }^{18-20}$ Thus, isolated primary pigmented nodular adrenocortical disease is sufficient for referral to genetic consultation. PRKAR1A mutations are found in $71 \%$ of individuals with at least two major diagnostic criteria for Carney complex ${ }^{18}$ (Table 3).

Referral should be considered for any individual with a personal history of or first-degree relative with (i) primary pigmented nodular adrenocortical disease or (ii) two or more diagnostic criteria ${ }^{21}$ (Table 3).

\section{Constitutional mismatch repair deficiency (OMIM 276300)}

Constitutional mismatch repair deficiency is a recessive condition caused by biallelic mutations in the mismatch repair genes ( $M L H 1, M S H 2$ (including methylation due to an EPCAM deletion), MSH6, and PMS2) and is characterized by a high risk of developing cancers during childhood, including Lynch syndrome (LS)-associated cancers, hematologic malignancies, and embryonic tumors. ${ }^{22}$ Individuals with constitutional mismatch repair deficiency have neurofibromatosis type 1-like features, with café-au-lait macules observed in most cases $^{23}$ and skinfold freckling, Lisch nodules, neurofibromas, and tibial pseudoarthosis reported in fewer cases. Individuals with constitutional mismatch repair deficiency do not always have a family history of cancer.

\section{Table 3 Carney complex criteria ${ }^{21}$}

- Spotty skin pigmentation on lips, conjunctiva and inner or outer canthi, and/or vaginal or penile mucosa

- Myxoma (cutaneous and mucosal)

- Cardiac myxoma

- Breast myxomatosis or fat-suppressed magnetic resonance imaging findings suggestive of this diagnosis

- Acromegaly due to growth hormone-producing adenoma

- Large cell calcifying Sertoli cell tumor or characteristic calcification on testicular ultrasonography

- Primary pigmented nodular adrenocortical dysplasia

- Thyroid carcinoma (nonmedullary) or multiple hypoechoic nodules on thyroid ultrasonography in a young patient

- Psammomatous melanotic schwannoma

- Blue nevus, epithelioid blue nevus (multiple)

- Breast ductal adenoma (multiple)

- Osteochondromyxoma
Referral should be considered for any individual with a personal history of or first-degree relative with (i) an LS-associated cancer in childhood or (ii) another type of childhood cancer and one or more of the following features: (i) café-au-lait macules, skinfold freckling, Lisch nodules, neurofibromas, tibial pseudoarthrosis, or hypopigmented skin lesions; (ii) family history of LS-associated cancer; (iii) a second primary cancer; (iv) a sibling with a childhood cancer; or (v) consanguineous parents.

\section{Cowden syndrome, also known as PTEN hamartoma tumor syndrome (OMIM 158350)}

Cowden syndrome is caused by mutations in the PTEN gene and is characterized by benign skin findings, increased lifetime risks for breast (30-85\%; often early-onset), follicular thyroid (10-38\%), renal cell (34\%), endometrial (5-28\%), and colorectal cancers (9\%), and possibly melanoma (6\%). ${ }^{24-28}$ Clinical diagnostic criteria involve combinations of major and minor criteria $^{29}$ (Table 4). We recommend referral for anyone meeting any three criteria from the major or minor diagnostic criteria.

Referral should be considered for any individual with a personal history of or first-degree relative with (i) LhermitteDuclos disease diagnosed after age 18 (ref. 30) or (ii) any three

Table 4 Cowden syndrome criteria (National Comprehensive Cancer Network, 2013)

\section{Major criteria}

- Breast cancer

- Endometrial cancer (epithelial)

- Thyroid cancer (follicular)

- Gastrointestinal hamartomas (including ganglioneuromas but excluding hyperplastic polyps; $\geq 3$ )

- Lhermitte-Duclos disease (adult)

- Macrocephaly ( $\geq 97$ th percentile: $58 \mathrm{~cm}$ for adult women, $60 \mathrm{~cm}$ for adult men)

- Macular pigmentation of the glans penis

- Multiple mucocutaneous lesions (any of the following):

-Multiple trichilemmomas ( $\geq 3$, at least 1 proven by biopsy)

-Acral keratoses ( $\geq 3$ palmoplantar keratotic pits and/or acral hyperkeratotic papules)

-Mucocutaneous neuromas ( $\geq 3$ )

-Oral papillomas (particularly on tongue and gingival), multiple ( $\geq 3$ ) OR biopsy proven OR dermatologist diagnosed

\section{Minor criteria}

- Autism spectrum disorder

- Colon cancer

- Esophageal glycogenic acanthosis ( $\geq 3)$

- Lipomas ( $\geq 3$ )

- Intellectual disability (i.e., intelligence quotient $\leq 75$ )

- Renal cell carcinoma

- Testicular lipomatosis

- Thyroid cancer (papillary or follicular variant of papillary)

- Thyroid structural lesions (e.g., adenoma, multinodular goiter)

- Vascular anomalies (including multiple intracranial developmental venous anomalies) 
criteria from the major or minor diagnostic criteria list in the same person $^{31}$ (Table 4).

\section{Familial adenomatous polyposis and attenuated familial adenomatous polyposis (OMIM 175100)}

Familial adenomatous polyposis (FAP) and attenuated FAP are caused by mutations in the APC gene and are characterized by adenomatous colon polyps and increased lifetime risk for colorectal cancer (nearly $100 \%$ for individuals with FAP and $70 \%$ for individuals with attenuated FAP). ${ }^{32}$ A clinical diagnosis of classic FAP is made when an individual has $>100$ adenomatous polyps in his or her colon. Attenuated FAP is characterized by 30-100 adenomatous polyps. Individuals with FAP are also at increased risk for duodenal (4-12\%), pancreatic ( 2\%), and papillary thyroid (cribriform morular variant $)^{33,34}(1-2 \%)^{29,30}$ cancers, as well as hepatoblastoma by age $5(1-2 \%)^{35,36}$ and medulloblastoma $(<1 \%){ }^{32}$ Extracolonic manifestations can include congenital hypertrophy of the retinal pigmented epithelium, osteomas, dental abnormalities, benign cutaneous lesions such as epidermoid cysts and fibromas, and desmoid tumors. APC mutations are found in $80 \%$ of patients with 1,000 or more adenomas, $56 \%$ of patients with 100-999 adenomas, $10 \%$ of patients with $20-99$ adenomas, and $5 \%$ of patients with $10-19$ adenomas. ${ }^{37}$

Referral should be considered for any individual with a personal history of or first-degree relative with (i) a total of $\geq 10$ adenomatous colon polyps with or without a colorectal or other FAP-associated cancer $^{38}$; (ii) a cribriform morular variant of papillary thyroid cancer; (iii) a desmoid tumor; or (iv) hepatoblastoma diagnosed before age 5 .

\section{Familial gastrointestinal stromal tumor (OMIM 606764)}

Familial gastrointestinal stromal tumor (GIST) is a rare condition associated with mutations in the KIT, PDGFRA, SDHB, and $S D H C$ genes. Individuals with germline mutations in KIT can have hyperpigmentation, mast cell tumors, or dysphagia. Large hands have been associated with PDGFRA mutations. Individuals with neurofibromatosis type 1 can also develop GISTs. Wild-type GISTs are defined as GISTs that do not have detectable mutations in KIT, PDGFRA, or BRAF. Of patients with sporadic wild-type GIST, $12 \%$ had $S D H B$ or $S D H C$ mutations, ${ }^{39}$ and in another series, $12 \%$ of wild-type GISTs had an SDHA mutation (all of which exhibited loss of the SDHA protein by immunohistochemistry). ${ }^{40}$ There are no published referral guidelines for this condition; recommendations were made based on expert opinion.

Referral should be considered for any individual with a personal history of or first-degree relative with (i) three or more close relatives with GIST; (ii) wild-type GIST; or (iii) individuals with three or more GISTs.

\section{Familial pancreatic cancer (OMIM 260350)}

Pancreatic cancer risk is increased in several known hereditary cancer syndromes such as Lynch syndrome, Peutz-Jeghers syndrome, FAP, hereditary melanoma, and hereditary breast-ovarian cancer syndrome. The most common cause of familial pancreatic cancer are mutations in the BRCA2 gene. Published studies of families with two or more pancreatic cancer diagnoses demonstrate that $2.8-17 \%$ of these families have a $B R C A 2$ gene mutation. ${ }^{41-44}$ Because of increased prevalence of $B R C A$ mutations, unselected individuals of Ashkenazi Jewish ancestry with pancreatic cancer have a $5.5-31 \%$ chance of having one of the three Ashkenazi Jewish founder mutations. ${ }^{45-47}$ Some families with familial pancreatic cancer also have mutations in the CDKN2A, PALB2, or ATM genes. PALB2 mutations occur in $0.9-3.7 \%$ of pancreatic cancer patients with at least one additional relative affected with pancreatic cancer. ${ }^{48-50} A T M$ mutations were found in $2.4 \%(4 / 166)$ of patients with familial pancreatic cancer and in $4.6 \%(4 / 87)$ of families with three or more affected individuals. ${ }^{51}$

Referral should be considered for any individual with a personal history of or first-degree relative with (i) Ashkenazi Jewish ancestry and pancreatic cancer at any age; (ii) pancreatic cancer and a close relative with pancreatic cancer; (iii) three or more cases of breast, ovarian, pancreatic, and/or aggressive prostate cancer; or (iv) three or more cases of pancreatic cancer and/or melanoma.

\section{Familial prostate cancer (OMIM 176807, 601518, 602759, 300147, 603688, 608656, and 153622)}

The genetic etiology of familial prostate cancer has proven difficult to characterize. Autosomal dominant, recessive, and $\mathrm{X}$-linked patterns of inheritance have been demonstrated in families with multiple cases of prostate cancer. ${ }^{14}$ For these guidelines, the Hopkins criteria ${ }^{52}$ have been adopted to define familial prostate cancer. Several studies have identified a specific HOXB13 mutation in $1.4-4.6 \%$ of individuals (primarily of Northern European ancestry) meeting these criteria. ${ }^{53-55}$ Identifying the basis of familial prostate cancer is ongoing, and genes found to date account for a small portion of families. However, referral may be appropriate for these families to help address concerns and provide screening recommendations.

Referral should be considered for any individual with a personal history of or first-degree relative with (i) three or more first-degree relatives with prostate cancer; (ii) two or more cases of prostate cancer diagnosed before age 55; or (iii) aggressive prostate cancer (Gleason score $\geq 7$ ) and two or more cases of breast, ovarian, or pancreatic cancer.

\section{Hereditary breast-ovarian cancer syndrome (OMIM 604370 and 612555)}

Hereditary breast-ovarian cancer (HBOC) syndrome is caused by mutations in the BRCA1 and BRCA2 genes and is characterized by increased risks for early-onset breast, multiple breast primaries, male breast, and epithelial ovarian, Fallopian tube, or primary peritoneal cancers. In addition, cancers of the pancreas, prostate, and melanoma are more common in individuals with HBOC syndrome. The pathology of "triple-negative phenotype" breast cancer (estrogen receptor-negative, progesterone receptor-negative, and HER2/neu-negative) has been strongly associated with BRCA1 mutations. ${ }^{56-59}$ The likelihood of identifying a $B R C A 1 / 2$ mutation in a woman with ovarian cancer at any age is around $13-18 \%{ }^{60-62}$ Of males with breast cancer, 
$15-20 \%$ have a BRCA1/2 mutation. ${ }^{63}$ The overall prevalence of $B R C A 1$ mutations is estimated at 1 in 300 and that of BRCA2 mutations is estimated at 1 in 800 , but founder mutations in many populations (e.g., Ashkenazi Jewish, ${ }^{64-67}$ Icelandic, ${ }^{68}$ and Mexican Hispanic ${ }^{69}$ populations) lead to increased mutation prevalence in these populations.

Referral should be considered for any individual with a personal history of or first-degree relative with (i) breast cancer diagnosed at or before age 50; (ii) triple-negative breast cancer diagnosed at or before age 60; (iii) two or more primary breast cancers in the same person; (iv) ovarian, Fallopian tube, or primary peritoneal cancer; (v) Ashkenazi Jewish ancestry and breast or pancreatic cancer at any age; or (vi) male breast cancer. Individuals with a family history of three or more cases of breast, ovarian, pancreatic, and/or aggressive prostate cancer (Gleason score $\geq 7$ ) (refs. 70,71 ) should also be referred. Note that this should not include families in which all three cases are aggressive prostate cancer.

\section{Hereditary diffuse gastric cancer (OMIM 137215)}

Hereditary diffuse gastric cancer is caused by mutations in the CDH1 gene and is characterized by an increased risk for diffuse gastric cancer, lobular breast cancer, and signet ring colorectal cancer. $\mathrm{CDH} 1$ mutations occur in $25-50 \%$ of individuals who meet the hereditary diffuse gastric cancer criteria. ${ }^{72}$ The International Gastric Cancer Linkage Consortium's most recent consensus guidelines for the clinical management of hereditary diffuse gastric cancer include indications for $\mathrm{CDH} 1$ testing and have been adopted below. ${ }^{73}$

Referral should be considered for any individual with a personal history of or first-degree relative with (i) diffuse gastric cancer diagnosed before age 40; (ii) lobular breast cancer and diffuse gastric cancer in the same person; (iii) lobular breast cancer in one relative and diffuse gastric cancer in another, one diagnosed before age 50; or (iv) two cases of gastric cancer in family, one of which is a confirmed diffuse gastric cancer diagnosed before age 50. Individuals with a family history of three or more relatives with gastric cancer should also be referred.

\section{Hereditary leiomyomatosis and renal cell cancer (OMIM 605839 and 150800)}

Hereditary leiomyomatosis and renal cell cancer is caused by mutations in the $\mathrm{FH}$ gene and is characterized by increased risks for renal cancer and cutaneous and uterine leiomyomas. Individuals with cutaneous leiomyoma and renal cell tumors of one of three types (papillary type 2 (refs. 74-78)), collecting duct, ${ }^{71,74,75}$ and tubulopapillary ${ }^{78}$ ) should receive genetic counseling referral. ${ }^{79,80}$ Although studies of the proportion of isolated cases of cutaneous leiomyomas with an $\mathrm{FH}$ mutation are not available, $85 \%$ of individuals with cutaneous leiomyomas (some of whom were isolated cases and some of whom had a family history of uterine leiomyoma or renal cell tumors) had an $F H$ mutation in several studies. ${ }^{74-77,81}$ A FH mutation was found in $17 \%$ of patients with papillary type 2 renal cell carcinoma (RCC).

Referral should be considered for any individual with a personal history of or first-degree relative with (i) cutaneous leiomyomas or (ii) RCC with histology characteristic of hereditary leiomyomatosis and renal cell cancer.

\section{Hereditary melanoma, also known as familial atypical mole and malignant melanoma (OMIM 155600)}

Hereditary melanoma is caused by mutations in the CDKN2A/ $A R F$ gene, which encodes $p 16$ and $p 14 A R F$, and the CDK4 gene. Hereditary melanoma is characterized by multiple melanocytic nevi (usually $>50$ ) and a family history of melanoma. Individuals with hereditary melanoma have a $17 \%$ risk for pancreatic cancer by age 75 (ref. 82). The penetrance for melanoma in families with CDKN2A mutations is at least $28 \%$, although it is perhaps as high as $91 \%$ in families with multiple cases. ${ }^{83-85}$ A review of 466 families with at least three cases of melanoma revealed $38 \%$ had $C D K N 2 A$ mutations. ${ }^{86}$ Penetrance and detection rate vary by geography. ${ }^{84}$ In addition, $2-3 \%$ of these families have mutations in CDK4 $(n=5)$ and p14ARF $(n=7)$. CDKN2A gene mutations seem to be rare in families with pancreatic cancer without any cases of melanoma ${ }^{44}$ but occur in up to $11 \%$ $(2 / 18)$ of families with both pancreatic cancer and melanoma. ${ }^{87}$

Referral should be considered for any individual with a personal history of or first-degree relative with (i) three or more melanomas in the same person or (ii) three or more cases of melanoma and/or pancreatic cancer.

\section{Hereditary mixed polyposis syndrome (OMIM 201228 and 610069)}

Hereditary mixed polyposis syndrome is characterized by multiple polyps of mixed histology (hyperplastic, adenomatous, and juvenile polyps), leading to an increased risk for colorectal cancer. The major gene(s) responsible for hereditary mixed polyposis syndrome have not been identified; however, some cases are caused by mutations in the BMPR1A gene. ${ }^{88-90}$ Also, a founder mutation involving the GREM1 gene was identified in Ashkenazi Jewish patients with hereditary mixed polyposis syndrome. ${ }^{91}$

Referral should be considered for any individual with a personal history of or first-degree relative with $\geq 10$ colorectal polyps with mixed histology.

\section{Hereditary papillary RCC (OMIM 605074)}

Hereditary papillary RCC is caused by mutations in the MET gene and is characterized by an increased risk of developing papillary type 1 RCC. In a series of 129 patients with papillary RCC, $6 \%$ (8/129) had a germline MET mutation. ${ }^{92}$ Because this tumor type is rare, our referral criteria are for anyone with a papillary type 1 RCC. Note that patients with a papillary type 2 RCC should be referred as well because of the possibility of hereditary leiomyomatosis and renal cell cancer.

Referral should be considered for any individual with a personal history of or first-degree relative with a papillary type 1 RCC.

\section{Hereditary paraganglioma-pheochromocytoma syndrome (OMIM 115310, 168000, 605373, 601650, 154950, and 613403)} Hereditary paraganglioma-pheochromocytoma syndrome is caused by mutations in the $S D H B, S D H D, S D H C, S D H A F 2$, 
$M A X$, and TMEM127 genes and is characterized by an increased risk for paragangliomas and pheochromocytomas. In multiple series of individuals with paragangliomas and pheochromocytomas, $8-25 \%$ had hereditary paraganglioma-pheochromocytoma syndrome due to a germline mutation in the $S D H B$, $S D H C$, or $S D H D$ genes. ${ }^{93-98}$ Rates of hereditary paragangliomapheochromocytoma syndrome in individuals with a positive family history or other clinical factors (e.g., multiple tumors, head and neck location) are considerably higher. ${ }^{93-97}$

Referral should be considered for any individual who has a personal history of or a first-degree relative with a paraganglioma or pheochromocytoma.

\section{Hereditary retinoblastoma (OMIM 180200)}

Hereditary retinoblastoma is caused by mutations in the $R B 1$ gene and is characterized by a malignant tumor of the retina, usually occurring before age 5 . It is estimated that about $40 \%$ of all retinoblastomas are hereditary. ${ }^{99}$ Individuals with a positive family history of retinoblastoma, bilateral tumors, and multifocal tumors have the highest chance to have hereditary retinoblastoma. ${ }^{99}$ Individuals with hereditary retinoblastoma can also have an increased risk for pinealoblastoma, ${ }^{100}$ osteosarcomas, sarcoma (especially radiogenic), and melanoma. ${ }^{101,102}$

Referral should be considered for any individual who has a personal history of or first-degree relative with a retinoblastoma.

\section{Juvenile polyposis syndrome (OMIM 174900)}

Juvenile polyposis syndrome is caused by mutations in the SMAD4 (20\%) and BMPR1A (20\%) genes ${ }^{103}$ and is characterized by juvenile-type hamartomatous polyps throughout the gastrointestinal (GI) tract. The term juvenile polyp refers to a specific histologic type of polyp, not the age at diagnosis. The risk for GI cancers (mainly colorectal cancer, although cancers of the stomach, upper GI tract, and pancreas have been reported) in families with juvenile polyposis syndrome ranges from 9 to $50 \%{ }^{104}$ Extraintestinal features such as valvular heart disease $(11 \%)$, telangiectasia or vascular anomalies $(9 \%$, all in SMAD4 carriers), and macrocephaly (11\%) can occur. ${ }^{105}$ Some individuals with juvenile polyposis syndrome due to mutations in the SMAD4 gene may also have symptoms of hereditary hemorrhagic telangiectasia. ${ }^{106,107}$

Referral should be considered for any individual with a personal history of or first-degree relative with (i) three to five cumulative histologically proven juvenile GI polyps ${ }^{108-110}$; (ii) any number of juvenile GI polyps with a positive family history of juvenile polyposis syndrome; or (iii) multiple juvenile polyps located throughout the GI tract. ${ }^{38,103}$

\section{Li-Fraumeni syndrome (OMIM 151623)}

Li-Fraumeni syndrome (LFS) is caused by mutations in the TP53 gene and is characterized by the core cancers of breast, brain, adrenocortex, and non-Ewing sarcoma, ${ }^{111}$ with onset often before age 50 and multiple primary tumors. ${ }^{112}$ Young age at diagnosis (before age 30) and the type of malignancy are good indicators of a TP53 mutation. ${ }^{113}$ In individuals diagnosed with an adrenocortical tumor or choroid plexus tumor at or before age 18, the likelihood of identifying a TP53 mutation approaches 80 and $100 \%$, respectively. ${ }^{112,114,115}$ Individuals with a childhood sarcoma have a higher likelihood of LFS; 6.6\% had a TP53 mutation in one series (although the majority of these cases would meet the classic LFS criteria). ${ }^{116}$ For these guidelines, we are adopting a combination of the Eeles and revised Chompret criteria. ${ }^{117}$ In two large studies, $29 \%{ }^{118}$ and $35 \%{ }^{112}$ of individuals who met the original, slightly more restrictive, Chompret criteria $^{119}$ had a TP53 mutation. However, $14 \%$ of individuals who met the looser Eeles criteria also had a TP53 mutation. ${ }^{112}$

Referral should be considered for any individual with a personal history of or first-degree relative with (i) two or more close relatives with a tumor in the LFS spectrum (Table 5), one diagnosed at or before age 45; (ii) breast cancer diagnosed before age 30; (iii) two or more LFS tumors in the same person, one diagnosed at or before age 45; (iv) adrenocortical tumor; (v) choroid plexus tumor; or (vi) childhood sarcoma. ${ }^{117}$

\section{Lynch syndrome (OMIM 120435 and 120436)}

Lynch syndrome (LS) is caused by mutations in the following mismatch repair genes: $M L H 1, M S H 2$ (including methylation due to an EPCAM deletion), MSH6, or PMS2; LS is characterized by increased lifetime risks for colorectal (40-80\%), endometrial (25-60\%), ovarian (4-24\%), and gastric (1-13\%) cancers. ${ }^{120,121}$ Individuals with LS can also have an increased risk for urothelial carcinoma, glioblastoma, and sebaceous, biliary, small bowel, and pancreatic adenocarcinomas ${ }^{122-125}$ (Table 6). The lifetime risks for cancer are lower in individuals with MSH6 and PMS2 mutations. ${ }^{121,125}$ Most tumors (77-89\%) from individuals with LS are characterized by microsatellite instability, which is an expansion or contraction of repetitive areas in the DNA, called microsatellites, due to defective mismatch repair. ${ }^{126}$ In addition, there are immunohistochemical antibodies available for the four mismatch repair proteins, and one or two of the proteins is absent in $83 \%$ of tumors from individuals with LS. ${ }^{126}$ One or both of these tumor screening tests are sometimes performed at the time of diagnosis for colorectal and endometrial cancer and can serve as an indication for referral for a LS evaluation. The most well-known criteria developed for LS include the Amsterdam criteria and the Bethesda guidelines, both of which have undergone revision. ${ }^{127-130}$ Yet neither of these criteria sufficiently considers the breadth of cancers associated with LS. Furthermore, they are complex and difficult to apply. Thus, the criteria selected for this referral guideline are

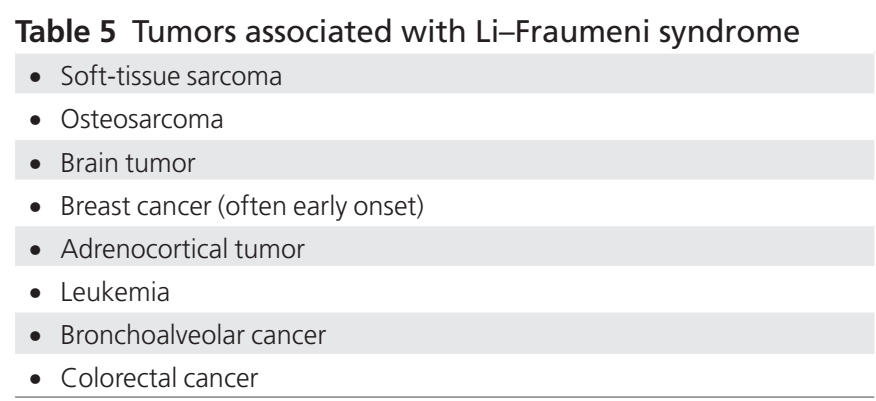


Table 6 Tumors associated with Lynch syndrome

- Colorectal adenocarcinoma

- Endometrial adenocarcinoma

- Urothelial carcinoma (ureter and renal collecting ducts)

- Gastric cancer

- Ovarian cancer

- Small bowel cancer

- Glioblastoma

- Sebaceous adenocarcinoma

- Biliary tract cancer

- Pancreatic cancer

modified from the "Finnish criteria," which are simple, easy to apply, based on two large population-based studies, and identify the majority of patients found to have LS. ${ }^{124,131-133}$

Referral should be considered for any individual with a personal history of or first-degree relative with (i) colorectal or endometrial cancer diagnosed before age 50; (ii) colorectal or endometrial cancer diagnosed at or after age 50 if there is a firstdegree relative with colorectal or endometrial cancer at any age; (iii) synchronous or metachronous colorectal or endometrial cancer; (iv) sebaceous adenoma or carcinoma and one or more additional case of any LS-associated cancer (Table 6) in the same person or in relatives; or (v) a tumor exhibiting mismatch repair deficiency (high microsatellite instability or loss of a mismatch repair protein based on immunohistochemical staining). Individuals with a family history of three or more LS-associated cancers (Table 6) should also be referred.

\section{Melanoma-astrocytoma syndrome (OMIM 155755)}

Melanoma-astrocytoma syndrome is caused by mutations involving both CDKN2A and P14ARF, p14ARF alone, and possibly the ANRIL antisense noncoding RNA; it is a rare condition that leads to an increased risk for melanoma and astrocytoma tumors.

Referral should be considered for any individual with a personal history of or first-degree relative with (i) melanoma and astrocytoma in the same person or (ii) one case of melanoma and one case of astrocytoma in two first-degree relatives.

\section{Multiple endocrine neoplasia type I (OMIM 131100)}

Multiple endocrine neoplasia type I (MEN1) is caused by mutations in the MEN1 gene and is characterized by increased risk of endocrine and nonendocrine tumors. ${ }^{134}$ Of individuals with two MEN1 manifestations, $26 \%$ had a MEN1 mutation. ${ }^{135}$ Because of the relatively low mutation detection rates in sporadic cases, ${ }^{134,136-139}$ no single MEN1-associated tumor is sufficient to warrant genetic counseling referral, with the exception of gastrinoma, of which $20 \%$ are due to MEN1 mutations. ${ }^{140}$ For this guideline, we are adopting the recommendation of the MEN1 International Consensus ${ }^{134}$ and the MEN1 Clinical Practice Guidelines. ${ }^{140}$ Note that this guideline is less stringent than the clinical diagnostic criteria for MEN1.
Referral should be considered for any individual with a personal history of or first-degree relative with (i) two or more different MEN1-associated tumors (adrenal, parathyroid, pituitary, pancreas, or thymic tumor or bronchial carcinoid tumor) in the same person ${ }^{134,141}$; (ii) gastrinoma ${ }^{134,140}$; (iii) multiple different pancreatic neuroendocrine tumors in the same per$\operatorname{son}^{134,140}$; (iv) parathyroid adenoma diagnosed before age 30 (refs. 140,142); (v) parathyroid adenomas involving multiple glands ${ }^{140,142}$; or (vi) parathyroid adenoma with family history of hyperparathyroidism or MEN1-associated tumors. ${ }^{142}$

\section{Multiple endocrine neoplasia type II (OMIM 171400, 155240 , and 162300)}

Multiple endocrine neoplasia type II (MEN2) is caused by mutations in the RET gene and is characterized by increased risks for medullary thyroid cancer (MTC) $(\leq 100 \%)$, pheochromocytomas $(\leq 50 \%)$, and parathyroid disease $(\leq 30 \%){ }^{143-145}$ As many as $25 \%$ of unselected individuals with MTC have a RET mutation. ${ }^{146}$ Individual series found that $4-11 \%$ of individuals with isolated MTC have a RET mutation. ${ }^{147-149}$ Genetic testing of individuals with nonsyndromic pheochromocytomas detected a RET mutation in 5\% of these individuals in one study, ${ }^{150}$ but lower rates were found in other studies. ${ }^{93,95}$ RET testing is not indicated in apparently sporadic hyperparathyroidism in the absence of other clinical suspicion for MEN2 (ref. 134). MEN2A accounts for $80 \%$ of hereditary MTC syndromes. ${ }^{151}$ Families with MTC and no other MEN2-associated tumors are referred to as having familial medullary thyroid cancer. ${ }^{143,152}$ Familial medullary thyroid cancer accounts for $15 \%$ of hereditary MTC syndromes. ${ }^{151}$ MEN2B accounts for $5 \%$ of hereditary MTC syndromes and is a more severe type of MEN2, differentiated by the presence of benign oral and submucosal neuromas and a distinct appearance (tall and lanky with an elongated face and large lips). ${ }^{151}$ Of individuals with MEN2B, 40\% have diffuse ganglioneuromatosis of the GI tract. The large majority of patients with MEN2B have mutations in exon 16 (M918T) and, less often, in exon 15 (A883F). There are genotype-phenotype correlations between the specific mutation in RET and the various clinical features.

Referral should be considered for any individual with a personal history of or first-degree relative with (i) MTC; (ii) pheochromocytoma; (iii) oral or ocular neuromas (lips, tongue, sclera, or eyelids); or (iv) diffuse ganglioneuromatosis of the GI tract.

\section{MUTYH-associated polyposis (OMIM 608456)}

$M U T Y H$-associated polyposis is a recessive condition caused by biallelic mutations in the MUTYH gene and is characterized by an increased risk for adenomatous colon polyps and colorectal cancer (80\%). ${ }^{153}$ Individuals with MUTYHassociated polyposis can develop only a few adenomatous colon polyps or they can have $>100$ adenomatous colon polyps. ${ }^{38,154}$ As a result, this condition can overlap with FAP, attenuated FAP, and LS. Testing is often ordered for both APC and MUTYH at the same time for patients with $\geq 10$ adenomatous colon polyps. MUTYH testing might also be appropriate for patients with colorectal cancer diagnosed before 
age 50 after LS has been ruled out (the tumor exhibits mismatch repair proficiency), as $0.8-6 \%$ have biallelic MUTYH mutations. ${ }^{155-158}$ Biallelic MUTYH mutations are found in 2\% of patients with $\geq 1,000$ adenomas, $7 \%$ of patients with 100 999 adenomas, $7 \%$ of patients with $20-99$ adenomas, and $4 \%$ of patients with $10-19$ adenomas. $^{37}$

Referral should be considered for any individual with a personal history of or first-degree relative with (i) $\geq 10$ cumulative adenomatous colon polyps with or without colorectal cancer or (ii) mismatch repair proficient (microsatellite stable and/or normal mismatch repair protein based on immunohistochemical staining) colorectal cancer diagnosed before age 50 .

\section{Nevoid basal cell carcinoma syndrome (OMIM 109400)}

Nevoid basal cell carcinoma syndrome is caused by mutations in the $\mathrm{PTCH}$ gene and is characterized by the presence of multiple jaw keratocysts beginning in the teens and multiple basal-cell carcinomas beginning in the 20s. Physical features such as macrocephaly, bossing of the forehead, coarse facial features, facial milia, and skeletal anomalies are present in most individuals with nevoid basal cell carcinoma syndrome (Table 7). Less common features include cardiac fibromas (2\%), ovarian fibromas (20\%), medulloblastoma (primitive neuroectodermal tumor; $5 \%)$. The diagnosis is made clinically when an individual has two major diagnostic criteria and one minor diagnostic criterion or one major and three minor diagnostic criteria ${ }^{159-161}$ (Table 7).

Referral should be considered for any individual with a personal history of or first-degree relative with any two criteria from the major or minor diagnostic criteria lists (Table 7).

\section{Peutz-Jeghers syndrome (OMIM 175200)}

Peutz-Jeghers syndrome (PJS) is caused by mutations in the STK11 gene and is characterized by mucocutaneous hyperpigmentation of the mouth, lips, nose, eyes, genitalia, or fingers; multiple hamartomatous polyps in the GI tract; and increased risks for colorectal (39\% between ages 15 and 64), pancreatic
(36\%), gastric (29\%), and small intestinal (13\%) cancers. In addition, there are increased risks for breast cancer (54\%), ovarian sex cord tumors with annular tubules $(21 \%)$, and adenoma malignum of the cervix (10\%) and the testes, especially Sertoli cell tumors (9\%). ${ }^{162} \mathrm{PJ}$ polyps are hamartomatous with glandular epithelium supported by smooth muscle cells contiguous with the muscularis mucosa.

Referral should be considered for any individual with a personal history of or first-degree relative with (i) two or more histologically confirmed PJ GI polyps; (ii) one or more PJ GI polyp and mucocutanous hyperpigmentation; (iii) ovarian sex cord tumor with annular tubules; (iv) adenoma malignum of the cervix; (v) Sertoli cell tumor; (vi) pancreatic cancer and one or more PJ GI polyp; (vii) breast cancer and one or more PJ GI polyp; or (viii) one or more PJ polyp and a positive family history of PJS.

\section{Rhabdoid tumor predisposition syndrome types I and II (OMIM 609322 and 613325)}

Rhabdoid tumor predisposition syndrome is characterized by an increased risk for rhabdoid tumors (rare and aggressive tumors of children). Rhabdoid tumor predisposition syndrome type I is caused by mutations in the SMARCB1 gene. Germline mutations in the SMARCB1 gene occurred in 35\% (26/115 and $35 / 100$ ) of patients with apparently sporadic childhood rhabdoid tumors. ${ }^{163,164}$ Only 10 of 61 parents harbored the germline mutation in both series combined, indicating a high proportion of germ cell mosaicism or de novo mutations in rhabdoid tumor predisposition syndrome type I. ${ }^{163,164}$ Rhabdoid tumor predisposition syndrome type II is caused by mutations in the SMARCA4 gene. In two small series of apparently nonfamilial small cell carcinoma of the ovary, hypercalcemic type (which is a rare, aggressive rhabdoid tumor affecting children and young women), germline mutations in SMARCA4 were found in $29 \%$ $(2 / 7)^{165}$ and $50 \%(6 / 12)^{166}$ of cases.

Referral should be considered for any individual with a personal history of or first-degree relative with a rhabdoid tumor, including small cell carcinoma of the ovary, hypercalcemic type.

Table 7 Nevoid basal cell carcinoma syndrome criteria

\section{Major criteria}

- Lamellar calcification of the falx in an individual younger than age 20

- Jaw keratocyst

- Palmar or plantar pits

- Multiple basal cell carcinomas (>5 in a lifetime) or a basal cell carcinoma diagnosed before age 30 (excluding basal cell carcinomas that develop after radiotherapy)

- First-degree relative with nevoid basal cell carcinoma syndrome

Minor criteria

- Childhood medulloblastoma (primitive neuroectodermal tumor)

- Lymphomesenteric or pleural cysts

- Macrocephaly (occipital frontal circumference $>97$ th percentile)

- Cleft lip or cleft palate

- Vertebral or rib anomalies observed on x-ray

- Preaxial or postaxial polydactyly

- Ovarian or cardiac fibromas

- Ocular anomalies (cataract, developmental defects, and pigmentary changes of the retinal epithelium) 


\section{Serrated polyposis syndrome (not in OMIM)}

Serrated polyposis syndrome is a syndrome characterized by serrated polyps (SPs) and an increased risk for colorectal cancer. SPs can be difficult to diagnose and include hyperplastic polyps, sessile SPs, or adenomas, as well as traditional serrated adenomas. For these guidelines we adopt the 2012 National Comprehensive Cancer Network modification (http://www.nccn.org/professionals/physician_gls/pdf/genetics_colon.pdf) of the 2000 World Health Organization criteria ${ }^{167}$ for the diagnosis of serrated polyposis syndrome. No causative mutations in BMPR1A, SMAD4, PTEN, MUTYH, or GREM1 were found in a series of 65 individuals with serrated polyposis syndrome; it is likely that this condition is caused by novel genes that have yet to be discovered. ${ }^{168}$ Although genetic testing may not be useful at present, a genetics referral is indicated because the diagnosis will affect future management, and other polyposis syndromes should be ruled out.

Referral should be considered for any individual with a personal history of or first-degree relative with (i) at least 5 SPs proximal to the sigmoid colon, 2 of which are $>1 \mathrm{~cm}$ in diameter, (ii) $>20$ SPs throughout the large bowel, ${ }^{38,169}$ or (iii) any number of SPs proximal to the sigmoid colon and a positive family history of serrated polyposis syndrome.

\section{Tuberous sclerosis complex (OMIM 191100)}

Tuberous sclerosis complex (TSC) is caused by mutations in the TSC1 and TSC2 genes and is characterized by brain, kidney, and heart tumors, as well as skin and neurological abnormalities, among others ${ }^{170,171}$ (Table 8). Brain lesions in TSC are complex and include subependymal nodules, cortical hamartomas, areas of focal cortical hypoplasia, and heterotopic gray matter. ${ }^{171,172}$ When cerebral cortical dysplasia and cerebral white matter migration lines occur together, they should be counted as one rather than two features of TSC. ${ }^{170,171}$ Renal lesions (angiomyolipomas and/or cysts) are usually present during childhood, and prevalence increases with age. ${ }^{171}$ About two-thirds of newborns with TSC have one or more cardiac rhabdomyomas; they are largest during the neonatal period and regress with time. ${ }^{173}$ Skin lesions occur in nearly $100 \%$ of individuals, although none are pathognomonic. ${ }^{170}$ Retinal lesions are present in $87 \%$ of individuals with TSC but may be difficult to detect without dilating the pupils and using indirect ophthalmoscopy. ${ }^{171,174}$ Interestingly, two-thirds to three-fourths of individuals with TSC have de novo mutations. ${ }^{171}$ Clinical diagnostic criteria involve combinations of major and minor criteria ${ }^{170,171}$ (Table 8). We recommend referral for anyone meeting any two criteria from the major or minor diagnostic criteria lists.

Referral should be considered for any individual with a personal history of or first-degree relative with any two criteria from the major or minor diagnostic criteria lists in the same person $^{170,171}$ (Table 8).

\section{Von Hippel-Lindau syndrome (OMIM 193300)}

Von Hippel-Lindau syndrome is caused by mutations in the $V H L$ gene and is characterized by RCC (clear cell histology), hemangioblastomas, pheochromocytomas, and endolymphatic sac tumors. Simplex cases of central nervous system hemangioblastoma, pheochromocytoma, and endolymphatic sac tumor are each sufficient to warrant genetic counseling referral. $V H L$ mutations are detected in $10-40 \%$ of individuals with isolated central nervous system hemangioblastoma, ${ }^{175} 46 \%$ of those with isolated retinal capillary hemangioma, ${ }^{176} 3-11 \%$ of those with isolated pheochromocytoma, ${ }^{93,95,96,150,175,177,178}$ and about $20 \%$ of those with an endolymphatic sac tumor. ${ }^{179-183}$ Single cases of unilateral, unifocal RCC diagnosed at or after age 50 are insufficient to warrant referral to genetic counseling. ${ }^{175,184}$

Referral should be considered for any individual with a personal history of or first-degree relative with (i) clear cell RCC if he or she (a) has bilateral or multifocal tumors, (b) is diagnosed before age 50 , or (c) has a close relative with clear cell RCC; (ii) central nervous system hemangioblastoma; (iii) pheochromocytoma; (iv) endolymphatic sac tumor, or (v) retinal capillary hemangioma.

\section{SUMMARY}

This document suggests referral guidelines for 28 of the most common hereditary cancer susceptibility syndromes. The tables are meant to aid busy clinicians, enabling them to quickly search by cancer type (Table 1 includes common cancers, Table 2 includes rare benign and malignant tumors) to find appropriate referral criteria for the various syndromes detailed throughout this guideline. After locating the cancer of interest in the table, practitioners can learn more about the associated syndrome by looking it up in the text of this document. We recommend that patients (or their affected relatives) meeting

\section{Table 8 Tuberous sclerosis complex criteria}

\section{Major criteria}

- Facial angiofibromas or forehead plaque

- Nontraumatic ungual or periungual fibroma

- Hypomelanotic macules ( $\geq 3$ )

- Shagreen patch (connective tissue nevus)

- Cortical tuber in the brain

- Subependymal glial nodule

- Subependymal giant cell astrocytoma

- Multiple retinal nodular hamartomas

- Cardiac rhabdomyomas, single or multiple

- Lymphangiomyomatosis

- Renal angiomyolipoma

Minor criteria

- Multiple, randomly distributed pits in dental enamel

- Hamartomatous rectal polyps

- Bone cysts

- "Confetti" skin lesions

- Multiple renal cysts

- Nonrenal hamartoma

- Cerebral white matter radial migration lines

- Retinal achromic patch

- Gingival fibromas

From refs. 170,171. 
any of the cancer genetics referral criteria be referred to a cancer genetics specialist. To find a cancer genetics expert, visit the National Cancer Institute Cancer Genetics Services Directory (http://www.cancer.gov/cancertopics/genetics/directory), the National Society of Genetic Counselors website (http://www. nsgc.org; use the "Find a Genetic Counselor" feature), or the American College of Genetics and Genomics website (http:// www.acmg.net; use the "Find Genetic Services" feature).

\section{ACKNOWLEDGMENTS}

Document approved by the ACMG Board of Directors 31 July 2014. Document approved by the NSGC Board of Directors 25 August 2014.

\section{DISCLOSURE}

H.H. has received grant support from Myriad Genetic Laboratories in the form of donated genetic testing she has received honoraria for speaking from Quest Diagnostics, InVitae Genetics, and Myriad Genetic Laboratories in the past 3 years. This has not impacted the referral guidelines. A.B. has received National Institutes of Health funding but reports that it does not conflict with the content of this practice guideline. R.P. has received grant support from Myriad Genetic Laboratories in the form of donated genetic testing G.W. was supported by institutional funds from the Vanderbilt University School of Medicine. A.B., G.W., and R.L.B. declare no conflict of interest.

\section{REFERENCES}

1. Bensend TA, Veach PM, Niendorf KB. What's the harm? Genetic counselor perceptions of adverse effects of genetics service provision by non-genetics professionals. J Genet Couns 2014;23:48-63.

2. Brierley KL, Blouch E, Cogswell W, et al. Adverse events in cancer genetic testing: medical, ethical, legal, and financial implications. Cancer J 2012;18:303-309.

3. Miller CE, Krautscheid P, Baldwin EE, et al. Genetic counselor review of genetic test orders in a reference laboratory reduces unnecessary testing. Am J Med Genet A 2014;164A:1094-1101.

4. American Gastroenterological Association medical position statement: hereditary colorectal cancer and genetic testing. Gastroenterol 2001;121: 195-197.

5. American Society of Clinical Oncology. American Society of Clinical Oncology policy statement update: genetic testing for cancer susceptibility. J Clin Oncol 2003;21:2397-2406

6. US Preventive Services Task Force. Genetic risk assessment and BRCA mutation testing for breast and ovarian cancer susceptibility: recommendation statement. Ann Intern Med 2005; 143:355-361.

7. American College of Obstetricians and Gynecologists; ACOG Committee on Practice Bulletins-Gynecology; ACOG Committee on Genetics; Society of Gynecologic Oncologists. ACOG Practice Bulletin No. 103: Hereditary breast and ovarian cancer syndrome. Obstet Gynecol 2009;113:957-966.

8. Evaluation of Genomic Applications in Practice and Prevention (EGAPP) Working Group. Recommendations from the EGAPP Working Group: genetic testing strategies in newly diagnosed individuals with colorectal cancer aimed at reducing morbidity and mortality from Lynch syndrome in relatives. Genet Med 2009;11:35-41.

9. Acheson LS, Wiesner GL, Zyzanski SJ, Goodwin MA, Stange KC. Family historytaking in community family practice: implications for genetic screening. Genet Med 2000;2:180-185.

10. Blumenthal $D$, Causino N, Chang $Y C$, et al. The duration of ambulatory visits to physicians. J Fam Pract 1999;48:264-271.

11. Wattendorf DJ, Hadley DW. Family history: the three-generation pedigree. Am Fam Physician 2005;72:441-448.

12. Qureshi N, Wilson B, Santaguida P, Carroll J, Allanson J, Ruiz Culebro C, Brouwers M, Raina P. Collection and Use of Cancer Family History in Primary Care. Evidence Report/Technology Assessment No. 159 (prepared by the McMaster University Evidence-based Practice Center, under Contract No.
290-02-0020). AHRQ Publication No. 08-E001. Rockville, MD: Agency for Healthcare Research and Quality. October 2007

13. Hampel H, Sweet K, Westman JA, Offit K, Eng C. Referral for cancer genetics consultation: a review and compilation of risk assessment criteria. J Med Genet 2004;41:81-91.

14. Lindor NM, McMaster ML, Lindor CJ, Greene MH. Concise handbook of familial cancer susceptibility syndromes - second edition. J Nat/ Cancer Inst Monogr 2008;2008:1-93.

15. Peutz-Jeghers Syndrome. McGarrity TJ, Amos Cl, Frazier ML, Wei C. In: Pagon RA, Adam MP, Ardinger HH, Bird TD, Dolan CR, Fong CT, Smith RJH, Stephens K, editors. GeneReviews ${ }^{\circledR}$ [Internet]. Seattle (WA): University of Washington, Seattle; 1993-2014. 2001. Feb 23 [updated 2013 Jul 25]. http:// www.ncbi.nlm.nih.gov/pubmed/20301443. PMID:20301443. Accessed 20 June 2013.

16. Toro JR, Pautler SE, Stewart L, et al. Lung cysts, spontaneous pneumothorax, and genetic associations in 89 families with Birt-Hogg-Dubé syndrome. Am J Respir Crit Care Med 2007;175:1044-1053.

17. Chiu HT, Garcia CK. Familial spontaneous pneumothorax. Curr Opin Pulm Med 2006;12:268-272.

18. Bertherat J, Horvath $A$, Groussin L, et al. Mutations in regulatory subunit type $1 A$ of cyclic adenosine 5'-monophosphate-dependent protein kinase (PRKAR1A): phenotype analysis in 353 patients and 80 different genotypes. J Clin Endocrinol Metab 2009;94:2085-2091.

19. Groussin L, Jullian E, Perlemoine K, et al. Mutations of the PRKAR1A gene in Cushing's syndrome due to sporadic primary pigmented nodular adrenocortical disease. J Clin Endocrinol Metab 2002;87:4324-4329.

20. Groussin L, Kirschner LS, Vincent-Dejean C, et al. Molecular analysis of the cyclic AMP-dependent protein kinase $A$ (PKA) regulatory subunit 1A (PRKAR1A) gene in patients with Carney complex and primary pigmented nodular adrenocortical disease (PPNAD) reveals novel mutations and clues for pathophysiology: augmented PKA signaling is associated with adrenal tumorigenesis in PPNAD. Am J Hum Genet 2002;71:1433-1442.

21. Stratakis CA, Kirschner LS, Carney JA. Clinical and molecular features of the Carney complex: diagnostic criteria and recommendations for patient evaluation. J Clin Endocrinol Metab 2001;86:4041-4046.

22. Ripperger T, Beger $\mathrm{C}$, Rahner N, et al. Constitutional mismatch repair deficiency and childhood leukemia/lymphoma-report on a novel biallelic MSH6 mutation. Haematologica 2010;95:841-844.

23. Wimmer K, Kratz CP. Constitutional mismatch repair-deficiency syndrome. Haematologica 2010;95:699-701.

24. Bubien V, Bonnet F, Brouste V, et al.; French Cowden Disease Network. High cumulative risks of cancer in patients with PTEN hamartoma tumour syndrome. J Med Genet 2013;50:255-263.

25. Tan MH, Mester JL, Ngeow J, Rybicki LA, Orloff MS, Eng C. Lifetime cancer risks in individuals with germline PTEN mutations. Clin Cancer Res 2012;18:400-407.

26. PTEN Hamartoma Tumor Syndrome (PHTS). Eng C. In: Pagon RA, Adam MP, Ardinger HH, Bird TD, Dolan CR, Fong CT, Smith RJH, Stephens K, editors. GeneReviews $₫$ [Internet]. Seattle (WA): University of Washington, Seattle; 1993-2014. 2001. Nov 29 [updated 2014 Jan 23]. http://www.ncbi.nlm.nih. gov/pubmed/20301661. PMID: 20301661.

27. Pilarski R, Stephens JA, Noss R, Fisher JL, Prior TW. Predicting PTEN mutations: an evaluation of Cowden syndrome and Bannayan-Riley-Ruvalcaba syndrome clinical features. J Med Genet 2011;48:505-512.

28. Heald B, Mester J, Rybicki L, Orloff MS, Burke CA, Eng C. Frequent gastrointestinal polyps and colorectal adenocarcinomas in a prospective series of PTEN mutation carriers. Gastroenterology 2010;139:1927-1933.

29. Pilarski R, Burt R, Kohlman W, Pho L, Shannon KM, Swisher E. Cowden syndrome and the PTEN hamartoma tumor syndrome: systematic review and revised diagnostic criteria. J Nat/ Cancer Inst 2013;105:1607-1616.

30. Zhou XP, Marsh DJ, Morrison CD, et al. Germline inactivation of PTEN and dysregulation of the phosphoinositol-3-kinase/Akt pathway cause human Lhermitte-Duclos disease in adults. Am J Hum Genet 2003;73:1191-1198.

31. Eng C. Will the real Cowden syndrome please stand up: revised diagnostic criteria. J Med Genet 2000;37:828-830.

32. Neklason DW, Stevens J, Boucher KM, et al. American founder mutation for attenuated familial adenomatous polyposis. Clin Gastroenterol Hepatol 2008;6:46-52.

33. Donnellan KA, Bigler SA, Wein RO. Papillary thyroid carcinoma and familial adenomatous polyposis of the colon. Am J Otolaryngol 2009;30:58-60.

34. Harach HR, Williams GT, Williams ED. Familial adenomatous polyposis associated thyroid carcinoma: a distinct type of follicular cell neoplasm. Histopathology 1994;25:549-561. 
35. Giardiello FM, Petersen GM, Brensinger JD, et al. Hepatoblastoma and APC gene mutation in familial adenomatous polyposis. Gut 1996;39:867-869.

36. Nieuwenhuis MH, Vasen HF. Correlations between mutation site in APC and phenotype of familial adenomatous polyposis (FAP): a review of the literature. Crit Rev Oncol Hematol 2007;61:153-161.

37. Grover S, Kastrinos F, Steyerberg EW, et al. Prevalence and phenotypes of APC and MUTYH mutations in patients with multiple colorectal adenomas. JAMA 2012;308:485-492.

38. Aretz $\mathrm{S}$. The differential diagnosis and surveillance of hereditary gastrointestinal polyposis syndromes. Dtsch Arzteb/ Int 2010;107:163-173.

39. Janeway KA, Kim SY, Lodish M, et al.; NIH Pediatric and Wild-Type GIST Clinic. Defects in succinate dehydrogenase in gastrointestinal stromal tumors lacking KIT and PDGFRA mutations. Proc Natl Acad Sci USA 2011;108:314-318.

40. Oudijk L, Gaal J, Korpershoek E, et al. SDHA mutations in adult and pediatric wild-type gastrointestinal stromal tumors. Mod Pathol 2013;26:456-463.

41. Couch FJ, Johnson MR, Rabe KG, et al. The prevalence of BRCA2 mutations in familial pancreatic cancer. Cancer Epidemiol Biomarkers Prev 2007;16: 342-346.

42. Hahn SA, Greenhalf B, Ellis I, et al. BRCA2 germline mutations in familial pancreatic carcinoma. J Natl Cancer Inst 2003;95:214-221.

43. Murphy KM, Brune KA, Griffin C, et al. Evaluation of candidate genes MAP2K4, MADH4, ACVR1B, and BRCA2 in familial pancreatic cancer: deleterious BRCA2 mutations in 17\%. Cancer Res 2002;62:3789-3793.

44. Slater EP, Langer $P$, Fendrich $V$, et al. Prevalence of BRCA2 and CDKN2a mutations in German familial pancreatic cancer families. Fam Cancer 2010;9:335-343.

45. Ferrone $C R$, Levine DA, Tang $L H$, et al. BRCA germline mutations in Jewish patients with pancreatic adenocarcinoma. J Clin Oncol 2009;27:433-438.

46. Lal G, Liu G, Schmocker B, et al. Inherited predisposition to pancreatic adenocarcinoma: role of family history and germ-line p16, BRCA1, and BRCA2 mutations. Cancer Res 2000;60:409-416.

47. Ozçelik H, Schmocker B, Di Nicola N, et al. Germline BRCA2 6174delT mutations in Ashkenazi Jewish pancreatic cancer patients. Nat Genet 1997;16:17-18.

48. Jones S, Hruban RH, Kamiyama M, et al. Exomic sequencing identifies PALB2 as a pancreatic cancer susceptibility gene. Science 2009;324:217.

49. Slater EP, Langer P, Niemczyk E, et al. PALB2 mutations in European familial pancreatic cancer families. Clin Genet 2010;78:490-494.

50. Tischkowitz MD, Sabbaghian N, Hamel N, et al. Analysis of the gene coding for the BRCA2-interacting protein PALB2 in familial and sporadic pancreatic cancer. Gastroenterology 2009;137:1183-1186.

51. Roberts NJ, Jiao Y, Yu J, et al. ATM mutations in patients with hereditary pancreatic cancer. Cancer Discov 2012;2:41-46.

52. Carter BS, Bova GS, Beaty TH, et al. Hereditary prostate cancer: epidemiologic and clinical features. J Urol 1993;150:797-802.

53. Ewing CM, Ray AM, Lange EM, et al. Germline mutations in HOXB13 and prostate-cancer risk. N Engl J Med 2012;366:141-149.

54. Karlsson R, Aly M, Clements M, et al. A population-based assessment of germline HOXB13 G84E mutation and prostate cancer risk. Eur Urol 2014;65:169-176.

55. Xu J, Lange EM, Lu L, et al.; International Consortium for Prostate Cancer Genetics. HOXB13 is a susceptibility gene for prostate cancer: results from the International Consortium for Prostate Cancer Genetics (ICPCG). Hum Genet 2013;132:5-14.

56. Gonzalez-Angulo AM, Timms KM, Liu S, et al. Incidence and outcome of BRCA mutations in unselected patients with triple receptor-negative breast cancer. Clin Cancer Res 2011;17:1082-1089.

57. Young SR, Pilarski RT, Donenberg T, et al. The prevalence of BRCA1 mutations among young women with triple-negative breast cancer. BMC Cancer 2009;9:86.

58. Fostira F, Tsitlaidou M, Papadimitriou C, et al. Prevalence of BRCA1 mutations among 403 women with triple-negative breast cancer: implications for genetic screening selection criteria: a Hellenic Cooperative Oncology Group Study. Breast Cancer Res Treat 2012;134:353-362.

59. Greenup R, Buchanan A, Lorizio W, et al. Prevalence of BRCA mutations among women with triple-negative breast cancer (TNBC) in a genetic counseling cohort. Ann Surg Oncol 2013;20:3254-3258.

60. Risch HA, McLaughlin JR, Cole DE, et al. Population BRCA1 and BRCA2 mutation frequencies and cancer penetrances: a kin-cohort study in Ontario, Canada. J Natl Cancer Inst 2006;98:1694-1706.

61. Risch HA, McLaughlin JR, Cole DE, et al. Prevalence and penetrance of germline BRCA1 and BRCA2 mutations in a population series of 649 women with ovarian cancer. Am J Hum Genet 2001;68:700-710.

62. Walsh T, Casadei S, Lee MK, et al. Mutations in 12 genes for inherited ovarian, fallopian tube, and peritoneal carcinoma identified by massively parallel sequencing. Proc Natl Acad Sci USA 2011;108:18032-18037.
63. Liede A, Karlan BY, Narod SA. Cancer risks for male carriers of germline mutations in BRCA1 or BRCA2: a review of the literature. J Clin Oncol 2004;22:735-742.

64. Neuhausen S, Gilewski T, Norton L, et al. Recurrent BRCA2 6174delT mutations in Ashkenazi Jewish women affected by breast cancer. Nat Genet 1996;13:126-128.

65. Offit K, Gilewski T, McGuire P, et al. Germline BRCA1 185delAG mutations in Jewish women with breast cancer. Lancet 1996;347:1643-1645.

66. Roa BB, Boyd AA, Volcik K, Richards CS. Ashkenazi Jewish population frequencies for common mutations in BRCA1 and BRCA2. Nat Genet 1996;14:185-187.

67. Struewing JP, Abeliovich D, Peretz T, et al. The carrier frequency of the BRCA1 185delAG mutation is approximately 1 percent in Ashkenazi Jewish individuals. Nat Genet 1995;11:198-200.

68. Johannesdottir G, Gudmundsson J, Bergthorsson JT, et al. High prevalence of the 999 del5 mutation in icelandic breast and ovarian cancer patients. Cancer Res 1996;56:3663-3665.

69. Weitzel JN, Lagos VI, Herzog JS, et al. Evidence for common ancestral origin of a recurring BRCA1 genomic rearrangement identified in high-risk Hispanic families. Cancer Epidemiol Biomarkers Prev 2007;16:1615-1620.

70. Castro E, Goh C, Olmos D, et al. Germline BRCA mutations are associated with higher risk of nodal involvement, distant metastasis, and poor survival outcomes in prostate cancer. J Clin Oncol 2013;31:1748-1757.

71. Mitra A, Fisher C, Foster CS, et al.; IMPACT and EMBRACE Collaborators. Prostate cancer in male BRCA1 and BRCA2 mutation carriers has a more aggressive phenotype. Br J Cancer 2008;98:502-507.

72. Seevaratnam R, Coburn N, Cardoso R, Dixon M, Bocicariu A, Helyer L. A systematic review of the indications for genetic testing and prophylactic gastrectomy among patients with hereditary diffuse gastric cancer. Gastric Cancer 2012;15(suppl 1):S153-S163.

73. Fitzgerald RC, Hardwick R, Huntsman D, et al.; International Gastric Cancer Linkage Consortium. Hereditary diffuse gastric cancer: updated consensus guidelines for clinical management and directions for future research. J Med Genet 2010;47:436-444.

74. Alam NA, Rowan AJ, Wortham NC, et al. Genetic and functional analyses of $\mathrm{FH}$ mutations in multiple cutaneous and uterine leiomyomatosis, hereditary leiomyomatosis and renal cancer, and fumarate hydratase deficiency. Hum Mol Genet 2003;12:1241-1252.

75. Martinez-Mir A, Glaser B, Chuang GS, et al. Germline fumarate hydratase mutations in families with multiple cutaneous and uterine leiomyomata. J Invest Dermatol 2003;121:741-744.

76. Tomlinson IP, Alam NA, Rowan AJ, et al.; Multiple Leiomyoma Consortium. Germline mutations in $\mathrm{FH}$ predispose to dominantly inherited uterine fibroids, skin leiomyomata and papillary renal cell cancer. Nat Genet 2002;30:406-410.

77. Toro JR, Nickerson ML, Wei MH, et al. Mutations in the fumarate hydratase gene cause hereditary leiomyomatosis and renal cell cancer in families in North America. Am J Hum Genet 2003;73:95-106.

78. Wei MH, Toure O, Glenn GM, et al. Novel mutations in FH and expansion of the spectrum of phenotypes expressed in families with hereditary leiomyomatosis and renal cell cancer. J Med Genet 2006;43:18-27.

79. Ponti G, Pellacani G, Seidenari S, Pollio A, Muscatello U, Tomasi A. Cancerassociated genodermatoses: skin neoplasms as clues to hereditary tumor syndromes. Crit Rev Oncol Hematol 2013;85:239-256.

80. Gardie B, Remenieras A, Kattygnarath D, et al.; French National Cancer Institute "Inherited predisposition to kidney cancer" network. Novel FH mutations in families with hereditary leiomyomatosis and renal cell cancer (HLRCC) and patients with isolated type 2 papillary renal cell carcinoma. J Med Genet 2011;48:226-234.

81. Alam NA, Olpin S, Leigh IM. Fumarate hydratase mutations and predisposition to cutaneous leiomyomas, uterine leiomyomas and renal cancer. Br J Dermatol 2005;153:11-17.

82. Mize DE, Bishop M, Resse E, Sluzevich J. Familial atypical multiple mole melanoma syndrome. In: Riegert-Johnson DL, Boardman LA, Hefferon T, Roberts M (eds). Cancer Syndromes [Internet]. National Center for Biotechnology Information: Bethesda, MD, 2009.

83. Begg CB, Orlow I, Hummer AJ, et al.; Genes Environment and Melanoma Study Group. Lifetime risk of melanoma in CDKN2A mutation carriers in a populationbased sample. J Natl Cancer Inst 2005;97:1507-1515.

84. Bishop DT, Demenais F, Goldstein AM, et al.; Melanoma Genetics Consortium. Geographical variation in the penetrance of CDKN2A mutations for melanoma. J Natl Cancer Inst 2002;94:894-903.

85. Cannon-Albright LA, Meyer LJ, Goldgar DE, et al. Penetrance and expressivity of the chromosome 9p melanoma susceptibility locus (MLM). Cancer Res 1994;54:6041-6044. 
86. Goldstein AM, Chan M, Harland M, et al.; Melanoma Genetics Consortium (GenoMEL). High-risk melanoma susceptibility genes and pancreatic cancer, neural system tumors, and uveal melanoma across GenoMEL. Cancer Res 2006;66:9818-9828.

87. Bartsch DK, Langer $\mathrm{P}$, Habbe $\mathrm{N}$, et al. Clinical and genetic analysis of 18 pancreatic carcinoma/melanoma-prone families. Clin Genet 2010;77: 333-341.

88. Cao X, Eu KW, Kumarasinghe MP, Li HH, Loi C, Cheah PY. Mapping of hereditary mixed polyposis syndrome (HMPS) to chromosome $10 q 23$ by genomewide high-density single nucleotide polymorphism (SNP) scan and identification of BMPR1A loss of function. J Med Genet 2006;43:e13.

89. Cheah PY, Wong YH, Chau YP, et al. Germline bone morphogenesis protein receptor $1 \mathrm{~A}$ mutation causes colorectal tumorigenesis in hereditary mixed polyposis syndrome. Am J Gastroentero/ 2009;104:3027-3033.

90. O'Riordan JM, O'Donoghue D, Green A, et al. Hereditary mixed polyposis syndrome due to a BMPR1A mutation. Colorectal Dis 2010;12:570-573.

91. Jaeger $E$, Leedham $S$, Lewis $A$, et al. Hereditary mixed polyposis syndrome is caused by a 40-kb upstream duplication that leads to increased and ectopic expression of the BMP antagonist GREM1. Nat Genet 2012;44:699-703.

92. Schmidt L, Junker K, Nakaigawa N, et al. Novel mutations of the MET protooncogene in papillary renal carcinomas. Oncogene 1999;18:2343-2350.

93. Amar L, Bertherat J, Baudin E, et al. Genetic testing in pheochromocytoma or functional paraganglioma. J Clin Oncol 2005;23:8812-8818.

94. Badenhop RF, Jansen JC, Fagan PA, et al. The prevalence of SDHB, SDHC, and SDHD mutations in patients with head and neck paraganglioma and association of mutations with clinical features. J Med Genet 2004;41:e99.

95. Erlic Z, Neumann HP. When should genetic testing be obtained in a patient with phaeochromocytoma or paraganglioma? Clin Endocrinol (Oxf) 2009;70: 354-357.

96. Mannelli M. Biochemistry, genetics and therapy of malignant pheochromocytomas. Ann Endocrinol (Paris) 2009;70:166-167.

97. Neumann HP, Erlic Z, Boedeker CC, et al. Clinical predictors for germline mutations in head and neck paraganglioma patients: cost reduction strategy in genetic diagnostic process as fall-out. Cancer Res 2009;69:3650-3656.

98. Neumann HP, Pawlu C, Peczkowska M, et al.; European-American Paraganglioma Study Group. Distinct clinical features of paraganglioma syndromes associated with SDHB and SDHD gene mutations. JAMA 2004;292:943-951.

99. Draper GJ, Sanders BM, Brownbill PA, Hawkins MM. Patterns of risk of hereditary retinoblastoma and applications to genetic counselling. Br J Cancer 1992;66:211-219.

100. Kivelä T. Trilateral retinoblastoma: a meta-analysis of hereditary retinoblastoma associated with primary ectopic intracranial retinoblastoma. J Clin Oncol 1999;17:1829-1837.

101. Kleinerman RA, Tucker MA, Abramson DH, Seddon JM, Tarone RE, Fraumeni JF Jr. Risk of soft tissue sarcomas by individual subtype in survivors of hereditary retinoblastoma. J Natl Cancer Inst 2007;99:24-31.

102. Moll AC, Imhof SM, Bouter LM, Tan KE. Second primary tumors in patients with retinoblastoma. A review of the literature. Ophthalmic Genet 1997; 18:27-34.

103. Howe JR, Haidle JL. Juvenile polyposis syndrome. In: Pagon R, Bird T, Dolon C, eds. GeneReviews [Internet]. University of Washington, Seattle, WA, 2008. http://www.ncbi.nlm.nih.gov/books/NBK1469/\#jps.REF.aretz.2007.702. Accessed 20 December 2010.

104. Howe JR, Roth S, Ringold JC, et al. Mutations in the SMAD4/DPC4 gene in juvenile polyposis. Science 1998;280:1086-1088.

105. Latchford AR, Neale K, Phillips RK, Clark SK. Juvenile polyposis syndrome: a study of genotype, phenotype, and long-term outcome. Dis Colon Rectum 2012;55:1038-1043.

106. Aretz S, Stienen D, Uhlhaas S, et al. High proportion of large genomic deletions and a genotype phenotype update in 80 unrelated families with juvenile polyposis syndrome. J Med Genet 2007:44:702-709.

107. Gallione CJ, Repetto GM, Legius E, et al. A combined syndrome of juvenile polyposis and hereditary haemorrhagic telangiectasia associated with mutations in MADH4 (SMAD4). Lancet 2004;363:852-859.

108. Giardiello FM, Hamilton SR, Kern SE, et al. Colorectal neoplasia in juvenile polyposis or juvenile polyps. Arch Dis Child 1991;66:971-975.

109. Jass JR, Williams CB, Bussey HJ, Morson BC. Juvenile polyposis-a precancerous condition. Histopathology 1988;13:619-630.

110. Nugent KP, Talbot IC, Hodgson SV, Phillips RK. Solitary juvenile polyps: not a marker for subsequent malignancy. Gastroenterology 1993;105:698-700.

111. Ognjanovic S, Olivier M, Bergemann TL, Hainaut P. Sarcomas in TP53 germline mutation carriers: a review of the IARC TP53 database. Cancer 2012;118:1387-1396.
112. Gonzalez KD, Noltner KA, Buzin CH, et al. Beyond Li Fraumeni Syndrome: clinical characteristics of families with p53 germline mutations. J Clin Oncol 2009;27:1250-1256.

113. Li-Fraumeni Syndrome. Schneider K, Zelley K, Nichols KE, Garber J. In: Pagon RA, Adam MP, Ardinger HH, Bird TD, Dolan CR, Fong CT, Smith RJH, Stephens K, editors. GeneReviews $\otimes$ [Internet] Seattle (WA): University of Washington, Seattle; 1993-2014. 1999. Jan 19 [updated 2013 Apr 11]. http://www.ncbi.nlm.nih.gov/pubmed/20301488. PMID:20301488.

114. Libé R, Bertherat J. Molecular genetics of adrenocortical tumours, from familial to sporadic diseases. Eur J Endocrinol 2005;153:477-487.

115. Varley JM, McGown G, Thorncroft M, et al. Are there low-penetrance TP53 alleles? Evidence from childhood adrenocortical tumors. Am J Hum Genet 1999;65:995-1006.

116. Hwang SJ, Lozano G, Amos Cl, Strong LC. Germline p53 mutations in a cohort with childhood sarcoma: sex differences in cancer risk. Am J Hum Genet 2003;72:975-983.

117. Ruijs MW, Verhoef S, Rookus MA, et al. TP53 germline mutation testing in 180 families suspected of Li-Fraumeni syndrome: mutation detection rate and relative frequency of cancers in different familial phenotypes. J Med Genet 2010;47:421-428.

118. Bougeard G, Sesboüé R, Baert-Desurmont S, et al.; French LFS working group. Molecular basis of the Li-Fraumeni syndrome: an update from the French LFS families. J Med Genet 2008;45:535-538.

119. Chompret A, Abel A, Stoppa-Lyonnet D, et al. Sensitivity and predictive value of criteria for p53 germline mutation screening. J Med Genet 2001;38:43-47.

120. Aarnio M, Sankila R, Pukkala E, et al. Cancer risk in mutation carriers of DNA-mismatch-repair genes. Int J Cancer 1999;81:214-218.

121. Bonadona V, Bonaïti B, Olschwang S, et al.; French Cancer Genetics Network. Cancer risks associated with germline mutations in MLH1, MSH2, and MSH6 genes in Lynch syndrome. JAMA 2011;305:2304-2310.

122. Hampel H, Stephens JA, Pukkala E, et al. Cancer risk in hereditary nonpolyposis colorectal cancer syndrome: later age of onset. Gastroenterology 2005;129:415-421.

123. Jenkins MA, Baglietto L, Dowty JG, et al. Cancer risks for mismatch repair gene mutation carriers: a population-based early onset case-family study. Clin Gastroenterol Hepatol 2006;4:489-498.

124. Salovaara R, Loukola A, Kristo P, et al. Population-based molecular detection of hereditary nonpolyposis colorectal cancer. J Clin Oncol 2000;18:2193-2200.

125. Senter L, Clendenning M, Sotamaa K, et al. The clinical phenotype of Lynch syndrome due to germ-line PMS2 mutations. Gastroenterology 2008; 135:419-428

126. Palomaki GE, McClain MR, Melillo S, Hampel HL, Thibodeau SN. EGAPP supplementary evidence review: DNA testing strategies aimed at reducing morbidity and mortality from Lynch syndrome. Genet Med 2009;11:42-65.

127. Boland CR, Thibodeau SN, Hamilton SR, et al. A National Cancer Institute Workshop on Microsatellite Instability for cancer detection and familial predisposition: development of international criteria for the determination of microsatellite instability in colorectal cancer. Cancer Res 1998;58: 5248-5257.

128. Umar A, Boland CR, Terdiman JP, et al. Revised Bethesda Guidelines for hereditary nonpolyposis colorectal cancer (Lynch syndrome) and microsatellite instability. J Natl Cancer Inst 2004;96:261-268.

129. Vasen HF, Mecklin JP, Khan PM, Lynch HT. The International Collaborative Group on Hereditary Non-Polyposis Colorectal Cancer (ICG-HNPCC). Dis Colon Rectum 1991;34:424-425.

130. Vasen HF, Watson P, Mecklin JP, Lynch HT. New clinical criteria for hereditary nonpolyposis colorectal cancer (HNPCC, Lynch syndrome) proposed by the International Collaborative group on HNPCC. Gastroenterology 1999;116:1453-1456.

131. Aaltonen LA, Salovaara R, Kristo P, et al. Incidence of hereditary nonpolyposis colorectal cancer and the feasibility of molecular screening for the disease. N Engl J Med 1998;338:1481-1487.

132. Hampel $H$, Frankel WL, Martin E, et al. Feasibility of screening for Lynch syndrome among patients with colorectal cancer. J Clin Oncol 2008;26: 5783-5788.

133. Hampel H, Frankel WL, Martin E, et al. Screening for the Lynch syndrome (hereditary nonpolyposis colorectal cancer). N Engl J Med 2005;352: $1851-1860$

134. Brandi ML, Gagel RF, Angeli A, et al. Guidelines for diagnosis and therapy of MEN type 1 and type 2. J Clin Endocrinol Metab 2001;86:5658-5671.

135. Odou MF, Cardot-Bauters C, Vantyghem MC, et al. Contribution of genetic analysis in screening for MEN1 among patients with sporadic disease and one or more typical manifestation. Ann Endocrinol (Paris) 2006;67:581-587. 
136. Marx SJ. Multiple endocrine neoplasia type 1. In: Scriver C, Beaudet A, Sly W, Valle D (eds). The Metabolic and Molecular Basis of Inherited Disease. 8th edn. McGraw-Hill: New York, 2001:943-966.

137. Schmidt MC, Henke RT, Stangl AP, et al. Analysis of the MEN1 gene in sporadic pituitary adenomas. J Pathol 1999;188:168-173.

138. Skandarajah A, Barlier A, Morlet-Barlat N, et al. Should routine analysis of the MEN1 gene be performed in all patients with primary hyperparathyroidism under 40 years of age? World J Surg 2010;34:1294-1298.

139. Uchino S, Noguchi S, Sato M, et al. Screening of the Men1 gene and discovery of germ-line and somatic mutations in apparently sporadic parathyroid tumors. Cancer Res 2000;60:5553-5557.

140. Thakker RV, Newey PJ, Walls GV, et al.; Endocrine Society. Clinical practice guidelines for multiple endocrine neoplasia type 1 (MEN1). J Clin Endocrinol Metab 2012;97:2990-3011.

141. Falchetti A. Genetic screening for multiple endocrine neoplasia syndrome type 1 (MEN-1): when and how. F1000 Med Rep 2010; e-pub 24 February 2010.

142. Kihara M, Miyauchi A, Ito $Y$, et al. MEN1 gene analysis in patients with primary hyperparathyroidism: 10-year experience of a single institution for thyroid and parathyroid care in Japan. Endocr J 2009;56:649-656.

143. Eng C, Clayton D, Schuffenecker I, et al. The relationship between specific RET proto-oncogene mutations and disease phenotype in multiple endocrine neoplasia type 2. International RET mutation consortium analysis. JAMA 1996;276:1575-1579.

144. Lefebvre M, Foulkes WD. Pheochromocytoma and paraganglioma syndromes: genetics and management update. Curr Onco/ 2014;21:e8-e17.

145. Moline J, Eng C. Multiple endocrine neoplasia type 2. In: Pagon RA, Adam MP, Bird TD, Dolan CR, Fong CT, Stephens K (eds). GeneReviews. University of Washington: Seattle, WA, 1993

146. Richards ML. Thyroid cancer genetics: multiple endocrine neoplasia type 2 , non-medullary familial thyroid cancer, and familial syndromes associated with thyroid cancer. Surg Oncol Clin N Am 2009;18:39-52, viii.

147. Elisei R, Romei $C$, Cosci $B$, et al. RET genetic screening in patients with medullary thyroid cancer and their relatives: experience with 807 individuals at one center. J Clin Endocrinol Metab 2007;92:4725-4729.

148. Erdogan MF, Gürsoy A, Ozgen G, et al. Ret proto-oncogene mutations in apparently sporadic Turkish medullary thyroid carcinoma patients: Turkmen study. J Endocrinol Invest 2005;28:806-809.

149. Bugalho MJ, Domingues R, Santos JR, Catarino AL, Sobrinho L. Mutation analysis of the RET proto-oncogene and early thyroidectomy: results of a Portuguese cancer centre. Surgery 2007;141:90-95.

150. Neumann HP, Bausch B, McWhinney SR, et al.; Freiburg-Warsaw-Columbus Pheochromocytoma Study Group. Germ-line mutations in nonsyndromic pheochromocytoma. N Engl J Med 2002;346:1459-1466.

151. Wells SA Jr, Pacini F, Robinson BG, Santoro M. Multiple endocrine neoplasia type 2 and familial medullary thyroid carcinoma: an update. J Clin Endocrino/ Metab 2013:98:3149-3164.

152. Kloos RT, Eng C, Evans DB, et al. Medullary thyroid cancer: management guidelines of the American Thyroid Association. Thyroid 2009;19:565-612.

153. Lipton L, Halford SE, Johnson V, et al. Carcinogenesis in MYH-associated polyposis follows a distinct genetic pathway. Cancer Res 2003;63:7595-7599.

154. Goodenberger M, Lindor NM. Lynch syndrome and MYH-associated polyposis: review and testing strategy. J Clin Gastroentero/ 2011;45:488-500.

155. Balaguer F, Castellví-Bel S, Castells A, et al.; Gastrointestinal Oncology Group of the Spanish Gastroenterological Association. Identification of MYH mutation carriers in colorectal cancer: a multicenter, case-control, population-based study. Clin Gastroenterol Hepatol 2007;5:379-387.

156. Lubbe SJ, Di Bernardo MC, Chandler IP, Houlston RS. Clinical implications of the colorectal cancer risk associated with MUTYH mutation. J Clin Oncol 2009:27:3975-3980.

157. Riegert-Johnson DL, Johnson RA, Rabe KG, et al. The value of MUTYH testing in patients with early onset microsatellite stable colorectal cancer referred for hereditary nonpolyposis colon cancer syndrome testing. Genet Test 2007:11:361-365.

158. Wang L, Baudhuin LM, Boardman LA, et al. MYH mutations in patients with attenuated and classic polyposis and with young-onset colorectal cancer without polyps. Gastroenterology 2004;127:9-16.

159. Evans DG, Farndon PA. Nevoid basal cell carcinoma syndrome. In: Pagon RA, Adam MP, Ardinger HH (eds). GeneReviews. University of Washington: Seattle, WA, 2002 (updated 7 March 2013) 2002.
160. Evans DG, Ladusans EJ, Rimmer S, Burnell LD, Thakker N, Farndon PA. Complications of the naevoid basal cell carcinoma syndrome: results of a population based study. J Med Genet 1993;30:460-464.

161. Kimonis VE, Goldstein AM, Pastakia B, et al. Clinical manifestations in 105 persons with nevoid basal cell carcinoma syndrome. Am J Med Genet 1997;69:299-308.

162. Giardiello FM, Brensinger JD, Tersmette AC, et al. Very high risk of cancer in familial Peutz-Jeghers syndrome. Gastroenterology 2000;119:1447-1453.

163. Bourdeaut F, Lequin D, Brugières $L$, et al. Frequent hSNF5/INI1 germline mutations in patients with rhabdoid tumor. Clin Cancer Res 2011;17:31-38.

164. Eaton KW, Tooke LS, Wainwright LM, Judkins AR, Biegel JA. Spectrum of SMARCB1/INI1 mutations in familial and sporadic rhabdoid tumors. Pediatr Blood Cancer 2011;56:7-15.

165. Ramos P, Karnezis AN, Craig DW, et al. Small cell carcinoma of the ovary, hypercalcemic type, displays frequent inactivating germline and somatic mutations in SMARCA4. Nat Genet 2014;46:427-429.

166. Witkowski L, Carrot-Zhang J, Albrecht S, et al. Germline and somatic SMARCA4 mutations characterize small cell carcinoma of the ovary, hypercalcemic type. Nat Genet 2014;46:438-443.

167. Burt R, Jass JR. Hyperplastic polyposis. In: Hamilton SR, Aaltonen LA (eds). Pathology and Genetics of Tumorurs of the Digestive System. ARC Press: Lyon, France, 2000:20-65

168. Clendenning M, Young JP, Walsh MD, et al. Germline mutations in the polyposis-associated genes BMPR1A, SMAD4, PTEN, MUTYH and GREM1 are not common in individuals with serrated polyposis syndrome. PLoS One 2013;8:e66705

169. Burt RW, Jass J. Hyperplastic polyposis. In: Hamilton SR, Aaltonen LA (eds). World Health Organisation Classification of Tumours Pathology and Genetics. Springer-Verlag: Berlin, Germany, 2000:135-136.

170. Roach ES, Gomez MR, Northrup H. Tuberous sclerosis complex consensus conference: revised clinical diagnostic criteria. J Child Neurol 1998;13:624-628.

171. Roach ES, Sparagana SP. Diagnosis of tuberous sclerosis complex. J Child Neurol 2004;19:643-649.

172. Weiner DM, Ewalt DH, Roach ES, Hensle TW. The tuberous sclerosis complex: a comprehensive review. J Am Coll Surg 1998;187:548-561.

173. DiMario FJ Jr, Diana D, Leopold H, Chameides L. Evolution of cardiac rhabdomyoma in tuberous sclerosis complex. Clin Pediatr (Phila) 1996;35: 615-619.

174. Kiribuchi K, Uchida Y, Fukuyama Y, Maruyama H. High incidence of fundus hamartomas and clinical significance of a fundus score in tuberous sclerosis. Brain Dev 1986:8:509-517.

175. Richard S, David P, Marsot-Dupuch K, Giraud S, Beroud C, Resche F. Central nervous system hemangioblastomas, endolymphatic sac tumors, and von Hippel-Lindau disease. Neurosurg Rev 2000;23:1-22; discussion 23-24.

176. Singh A, Shields J, Shields C. Solitary retinal capillary hemangioma: hereditary (von Hippel-Lindau disease) or nonhereditary? Arch Ophthalmol 2001;119:232-234

177. Brauch $\mathrm{H}$, Hoeppner W, Jähnig $H$, et al. Sporadic pheochromocytomas are rarely associated with germline mutations in the vhl tumor suppressor gene or the ret protooncogene. J Clin Endocrinol Metab 1997;82:4101-4104.

178. van der Harst E, de Krijger RR, Dinjens WN, et al. Germline mutations in the vhl gene in patients presenting with phaeochromocytomas. Int J Cancer 1998;77:337-340.

179. Gaffey MJ, Mills SE, Boyd JC. Aggressive papillary tumor of middle ear/temporal bone and adnexal papillary cystadenoma. Manifestations of von Hippel-Lindau disease. Am J Surg Pathol 1994;18:1254-1260.

180. Irving RM. The molecular pathology of tumours of the ear and temporal bone J Laryngol Otol 1998;112:1011-1018.

181. Poe DS, Tarlov EC, Thomas CB, Kveton JF. Aggressive papillary tumors of temporal bone. Otolaryngol Head Neck Surg 1993;108:80-86.

182. Tibbs RE Jr, Bowles AP Jr, Raila FA, Fratkin JD, Hutchins JB. Should endolymphatic sac tumors be considered part of the von Hippel-Lindau complex? Pathology case report. Neurosurgery 1997:40:848-855; discussion 855.

183. Megerian CA, McKenna MJ, Nuss RC, et al. Endolymphatic sac tumors: histopathologic confirmation, clinical characterization, and implication in von Hippel-Lindau disease. Laryngoscope 1995;105(8 Pt 1):801-808.

184. Neumann HP, Bender BU, Berger DP, et al. Prevalence, morphology and biology of renal cell carcinoma in von Hippel-Lindau disease compared to sporadic rena cell carcinoma. J Urol 1998;160:1248-1254. 